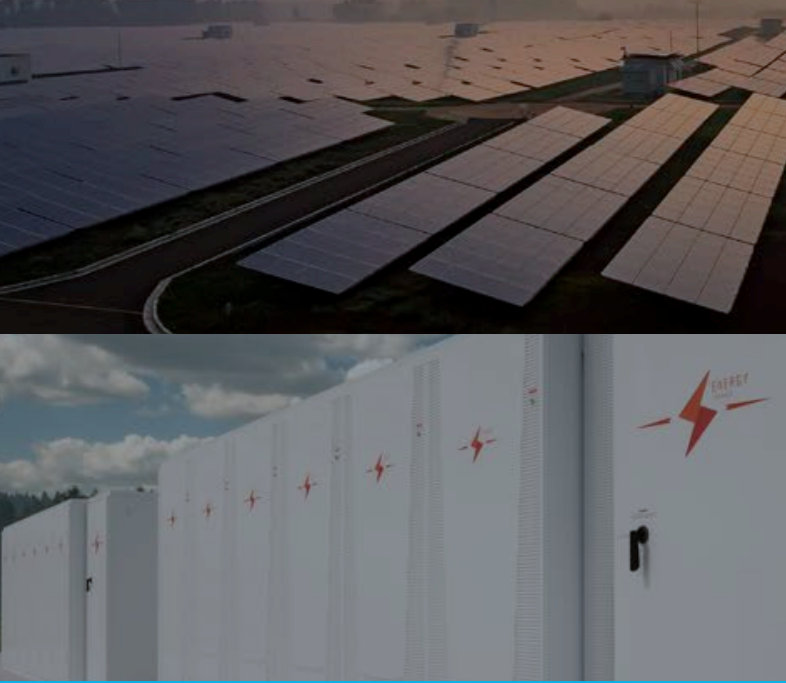

Storage Futures Study

The Four Phases of Storage Deployment: A Framework for the Expanding Role of Storage in the U.S. Power System

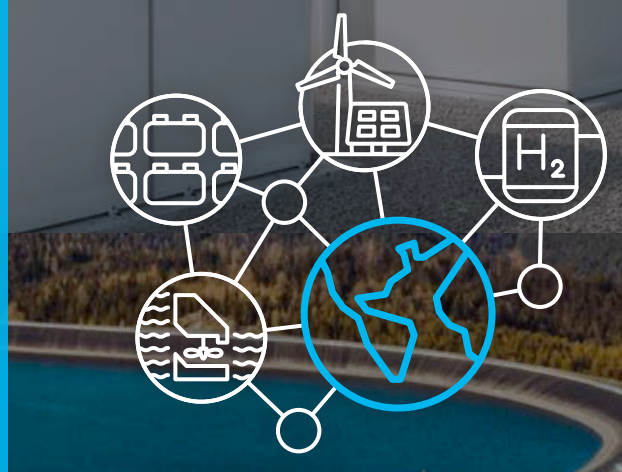




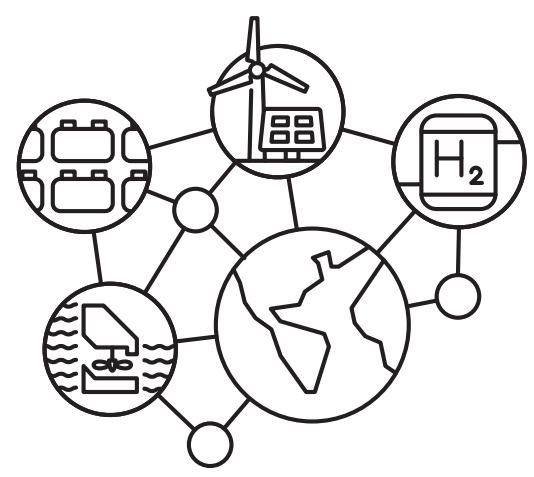

Storage Futures Study

\section{The Four Phases of Storage Deployment: A Framework for the Expanding Role of Storage in the U.S. Power System}

Paul Denholm, Wesley Cole, A. Will Frazier, Kara Podkaminer, and Nate Blair 


\section{NOTICE}

This work was authored by the National Renewable Energy Laboratory, operated by Alliance for Sustainable Energy, LLC, for the U.S. Department of Energy (DOE) under Contract No. DE-AC36-08GO28308. Funding provided by the U.S. Department of Energy Office of Energy Efficiency and Renewable Energy. The views expressed herein do not necessarily represent the views of the DOE or the U.S. Government.

This report is available at no cost from the National Renewable Energy Laboratory (NREL) at www.nrel.gov/publications.

U.S. Department of Energy (DOE) reports produced after 1991 and a growing number of pre-1991 documents are available free via www.OSTI.gov.

NREL prints on paper that contains recycled content. 


\section{Preface}

This report is one in a series of NREL's Storage Futures Study (SFS) publications. The SFS is a multiyear research project that explores the role and impact of energy storage in the evolution and operation of the U.S. power sector. The SFS is designed to examine the potential impact of energy storage technology advancement on the deployment of utility-scale storage and the adoption of distributed storage, and the implications for future power system infrastructure investment and operations. The research findings and supporting data will be published as a series of publications. The table on the next page lists the planned publications and specific research topics they will examine under the SFS.

This report, the first in the SFS series, explores the roles and opportunities for new, costcompetitive stationary energy storage with a conceptual framework based on four phases of current and potential future storage deployment, and presents a value proposition for energy storage that could result in substantial new cost-effective deployments. This conceptual framework provides a broader context for consideration of the later reports in the series, including the detailed results of the modeling and analysis of power system evolution scenarios and their operational implications.

The SFS series provides data and analysis in support of the U.S. Department of Energy's Energy Storage Grand Challenge, a comprehensive program to accelerate the development, commercialization, and utilization of next-generation energy storage technologies and sustain American global leadership in energy storage. The Energy Storage Grand Challenge employs a use case framework to ensure storage technologies can cost-effectively meet specific needs, and it incorporates a broad range of technologies in several categories: electrochemical, electromechanical, thermal, flexible generation, flexible buildings, and power electronics.

More information, any supporting data associated with this report, links to other reports in the series, and other information about the broader study are available at https://www.nrel.gov/analysis/storage-futures.html. 


\begin{tabular}{|c|c|c|}
\hline Title $^{a}$ & Description & Relation to this Report \\
\hline $\begin{array}{l}\text { The Four Phases of } \\
\text { Storage Deployment: } \\
\text { A Framework for the } \\
\text { Expanding Role of } \\
\text { Storage in the U.S. } \\
\text { Power System }\end{array}$ & $\begin{array}{l}\text { Explores the roles and opportunities for } \\
\text { new, cost-competitive stationary energy } \\
\text { storage with a conceptual framework } \\
\text { based on four phases of current and } \\
\text { potential future storage deployment, and } \\
\text { presents a value proposition for energy } \\
\text { storage that could result in cost-effective } \\
\text { deployments reaching hundreds of } \\
\text { gigawatts (GW) of installed capacity }\end{array}$ & Presented in this report \\
\hline $\begin{array}{l}\text { Energy Storage } \\
\text { Technology Modeling } \\
\text { Input Data Report }\end{array}$ & $\begin{array}{l}\text { Reviews the current characteristics of a } \\
\text { broad range of mechanical, thermal, and } \\
\text { electrochemical storage technologies with } \\
\text { application to the power sector. Provides } \\
\text { current and future projections of cost, } \\
\text { performance characteristics, and locational } \\
\text { availability of specific commercial } \\
\text { technologies already deployed, including } \\
\text { lithium-ion battery systems and pumped } \\
\text { storage hydropower. }\end{array}$ & $\begin{array}{l}\text { Provides storage technology } \\
\text { cost and performance } \\
\text { assumptions that inform } \\
\text { storage deployment and grid } \\
\text { evolution scenarios to test the } \\
\text { explanatory power of the } \\
\text { conceptual framework } \\
\text { presented in this report }\end{array}$ \\
\hline $\begin{array}{l}\text { Economic Potential of } \\
\text { Diurnal Storage in the } \\
\text { U.S. Power Sector } \\
\text { (Journal Article) }\end{array}$ & $\begin{array}{l}\text { Assesses the economic potential for utility- } \\
\text { scale diurnal storage and the effects that } \\
\text { storage capacity additions could have on } \\
\text { power system evolution and operations }\end{array}$ & $\begin{array}{l}\text { Analyzes utility-scale storage } \\
\text { deployment and grid } \\
\text { evolution scenarios to test the } \\
\text { explanatory power of the } \\
\text { conceptual framework } \\
\text { presented in this report }\end{array}$ \\
\hline $\begin{array}{l}\text { Distributed Storage } \\
\text { Customer Adoption } \\
\text { Scenarios }\end{array}$ & $\begin{array}{l}\text { Assesses the customer adoption of } \\
\text { distributed diurnal storage for several } \\
\text { future scenarios and the implications for } \\
\text { the deployment of distributed generation } \\
\text { and power system evolution }\end{array}$ & $\begin{array}{l}\text { Analyzes distributed storage } \\
\text { adoption scenarios to test the } \\
\text { explanatory power of the } \\
\text { conceptual framework } \\
\text { presented in this report }\end{array}$ \\
\hline $\begin{array}{l}\text { Grid Operational } \\
\text { Implications of } \\
\text { Widespread Storage } \\
\text { Deployment }\end{array}$ & $\begin{array}{l}\text { Assesses the operation and associated } \\
\text { value streams of energy storage for } \\
\text { several power system evolution scenarios } \\
\text { and explores the implications of seasonal } \\
\text { storage on grid operations }\end{array}$ & $\begin{array}{l}\text { Considers the operational } \\
\text { implications of storage } \\
\text { deployment and grid } \\
\text { evolution scenarios to test the } \\
\text { explanatory power of the } \\
\text { conceptual framework } \\
\text { presented in this report }\end{array}$ \\
\hline $\begin{array}{l}\text { Storage Futures Study: } \\
\text { Executive Summary and } \\
\text { Synthesis of Findings }\end{array}$ & $\begin{array}{l}\text { Synthesizes and summarizes findings from } \\
\text { the entire series and related analyses and } \\
\text { reports, and identifies topics for further } \\
\text { research }\end{array}$ & $\begin{array}{l}\text { Includes a discussion of the } \\
\text { usefulness of the conceptual } \\
\text { framework presented in this } \\
\text { report in explaining the } \\
\text { results of the storage } \\
\text { deployment and grid } \\
\text { evolution scenario and } \\
\text { operational analyses }\end{array}$ \\
\hline
\end{tabular}

a All publications are NREL technical reports unless noted. 


\section{Acknowledgements}

The authors would like to thank the following individuals for their contributions. Editing and graphics support were provided by Devonie McCamey, Mike Meshek, and Al Hicks. Supplemental analysis was provided by Jake Nunemaker and Michael Emmanuel. Helpful review and comments were provided by Doug Arent, Dominique Bain, Sam Baldwin, Dan Bilello, Sam Bockenhauer, Adria Brooks, Sarah Garman, Eric Hsieh, Kathryn Jackson, Cara Marcy, Alejandro Moreno, Keith Parks, Gian Porro, Neha Rustagi, Greg Stark, and Ryan Wiser. 


$\begin{array}{ll}\text { List of Acronyms and Abbreviations } \\ \text { B/C } & \text { benefit-cost } \\ \text { CAISO } & \text { California Independent System Operator } \\ \text { CCS } & \text { carbon capture and storage } \\ \text { ERCOT } & \text { Electric Reliability Council of Texas } \\ \text { FRCC } & \text { Florida Reliability Coordinating Council } \\ \text { GW } & \text { gigawatts } \\ \text { ISO } & \text { independent system operator } \\ \text { ISO-NE } & \text { ISO New England } \\ \text { kWh } & \text { kilowatt-hour (either a unit of energy or a unit of storage capacity) } \\ \text { kw-yr } & \text { kilowatt of capacity available for 1 year } \\ \text { LCOE } & \text { levelized cost of energy } \\ \text { LCOS } & \text { levelized cost of storage } \\ \text { MISO } & \text { Midcontinent Independent System Operator } \\ \text { MW } & \text { megawatts } \\ \text { MWh } & \text { megawatt-hour (energy) } \\ \text { MW-hr } & \text { megawatt of capacity available for 1 hour } \\ \text { NREL } & \text { National Renewable Energy Laboratory } \\ \text { NYISO } & \text { New York Independent System Operator } \\ \text { PV } & \text { photovoltaics } \\ \text { PSH } & \text { pumped storage hydropower } \\ \text { RE } & \text { renewable energy } \\ \text { SPP } & \text { Southwest Power Pool } \\ \text { VRE } & \text { variable renewable energy } \\ \text { WECC } & \text { Western Electricity Coordinating Council }\end{array}$




\section{Executive Summary}

The U.S. electricity system currently has about $24 \mathrm{GW}$ of stationary energy storage with the majority of it being in the form of pumped storage hydropower (PSH). Given changing technologies and market conditions, the deployment expected in the coming decades is likely to include a mix of technologies. Declining costs of energy storage are increasing the likelihood that storage will grow in importance in the U.S. power system. This work uses insights from recent deployment trends, projections, and analyses to develop a framework that characterizes the value proposition of storage as a way to help utilities, regulators, and developers be better prepared for the role storage might play and to understand the need for careful analysis to ensure cost-optimal storage deployment.

To explore the roles and opportunities for new cost-competitive stationary energy storage, we use a conceptual framework based on four phases of current and potential future storage deployment (see Table ES-1). The four phases, which progress from shorter to longer duration, link the key metric of storage duration to possible future deployment opportunities, considering how the cost and value vary as a function of duration.

Table ES-1. Summary of the Four Phases of Storage Deployment

\begin{tabular}{|c|c|c|c|c|}
\hline Phase & Primary Services & $\begin{array}{l}\text { National Deployment Potential } \\
\text { (Capacity) in Each Phase }\end{array}$ & Duration & $\begin{array}{l}\text { Response } \\
\text { Speed }\end{array}$ \\
\hline $\begin{array}{l}\text { Deployment } \\
\text { prior to } \\
2010\end{array}$ & $\begin{array}{l}\text { Peaking capacity, } \\
\text { energy time-shifting } \\
\text { and operating reserves }\end{array}$ & $23 \mathrm{GW}$ of $\mathrm{PSH}$ & $\begin{array}{l}\text { Mostly } \\
8-12 \mathrm{hr}\end{array}$ & Varies \\
\hline 1 & Operating reserves & $<30 \mathrm{GW}$ & $<1 \mathrm{hr}$ & $\begin{array}{l}\text { Milliseconds } \\
\text { to seconds }\end{array}$ \\
\hline 2 & Peaking capacity & $\begin{array}{l}\text { 30-100 GW, strongly linked } \\
\text { to PV deployment }\end{array}$ & $2-6 \mathrm{hr}$ & Minutes \\
\hline 3 & $\begin{array}{l}\text { Diurnal capacity and } \\
\text { energy time shifting }\end{array}$ & $\begin{array}{l}100+G W \text {. Depends on both on } \\
\text { Phase } 2 \text { and deployment of VRE } \\
\text { resources }\end{array}$ & $4-12 \mathrm{hr}$ & Minutes \\
\hline 4 & $\begin{array}{l}\text { Multiday to seasonal } \\
\text { capacity and energy } \\
\text { time-shifting }\end{array}$ & Zero to more than $250 \mathrm{GW}$ & $>12 \mathrm{hr}$ & Minutes \\
\hline
\end{tabular}

The 23 GW of PSH in the United States was built mostly before 1990 to provide peaking capacity and energy time-shifting for large, less flexible capacity. The economics of PSH allowed for deployment with multiple hours of capacity that allowed it to provide multiple grid services. These plants continue to provide valuable grid services that span the four phases framework, and their use has evolved to respond to a changing grid. However, a variety of 
factors led to a multidecade pause in new development with little storage deployment occurring from about 1990 until 2011.

Changing market conditions, such as the introduction of wholesale electricity markets and new technologies suggest storage deployment since 2011 may follow a somewhat different path, diverging from the deployment of exclusively 8+hour PSH. Instead, more recent deployment of storage has largely begun with shorter-duration storage, and we anticipate that new storage deployment will follow a trend of increasing durations.

We characterize this trend in our four phases framework, which captures how both the cost and value of storage changes as a function of duration. Many storage technologies have a significant cost associated with increasing the duration, or actual energy stored per unit of power capacity. In contrast, the value of most grid services does not necessarily increase with increasing asset duration - it may have no increase in value beyond a certain duration, or its value may increase at a rapidly diminishing rate. As a result, the economic performance of most storage technologies will rapidly decline beyond a certain duration. In current U.S. electricity markets, the value of many grid services can be captured by discrete and relatively short-duration storage (such as less than 1 hour for most operating reserves or 4 hours for capacity).

Together, the increasing cost of storage with duration and the lack of incremental value with increasing storage duration will likely contribute to growth of storage in the U.S. power sector that is characterized by a progression of deployments that aligns duration with specific services and storage technologies.

The four phases conceptual framework introduced in this work is a simplification of a more complicated evolution of the stationary energy storage industry and the power system as a whole. While we present four distinct phases, the boundaries between each phase will be somewhat indistinct and transitions between phases will occur at different times in different regions as various markets for specific services are saturated, and phases can overlap within a region. These transitions and the total market sizes are strongly influenced by the regional deployment of variable renewable energy (VRE) as well as hybrid deployments. However, we believe it is a useful framework to consider the role of different storage technologies, and particularly the importance of duration in driving adoption in each phase.

Phase 1, which began around 2011, is characterized by the deployment of storage with 1-hour or shorter duration, and it resulted from the emergence of restructured markets and new technologies that allow for cost-competitive provision of operating reserves, including regulating reserves. Potential deployment of short-duration storage in Phase 1 is bounded by the overall requirements for operating reserves, which is less than $30 \mathrm{GW}$ in the United States even when including regulating reserves, spinning contingency reserves, and frequency responsive reserves, some of which are not yet a widely compensated service.

\footnotetext{
${ }^{1}$ See Figure 1 in the main text.
} 
Phase 2 is characterized by the deployment of storage with 2-6 hours of discharge duration to serve as peaking capacity. Phase 2 has begun in some regions, with lithium-ion batteries becoming cost-competitive where durations of 2-6 hours are sufficient to provide reliable peaking capacity. As prices continue to fall, batteries are expected to become cost-competitive in more locations. These storage assets derive much of their value from the replacement of traditional peaking resources, (primarily natural gas-fired combustion turbines), but they also take value from time-shifting/energy arbitrage of energy supply. The potential opportunities of Phase 2 are limited by the local or regional length of the peak demand period and have a lower bound of about $40 \mathrm{GW}$. However, the length of peak demand is highly affected by the deployment of VRE, specifically solar photovoltaics (PV), which narrows the peak demand period. Phase 2 is characterized in part by the positive feedback between PV increasing the value of storage (increasing its ability to provide capacity) and storage increasing the value of PV (increasing its energy value by shifting it output to periods of greater demand). Thus, greater deployment of solar PV could extend the storage potential of Phase 2 to more than $100 \mathrm{GW}$ in the United States in scenarios where $25 \%$ of the nation's electricity is derived from solar.

Phase 3 is less distinct, but is characterized by lower costs and technology improvements that enable storage to be cost-competitive while serving longer-duration (4-12 hour) peaks. These longer net load peaks can result from the addition of substantial 2-6 hour storage deployed in Phase 2. Deployment in Phase 3 could include a variety of new technologies and could also see a reemergence of pumped storage, taking advantage of new technologies that reduce costs and siting constraints while exploiting the $8+$ hour durations typical of many pumped storage facilities. The technology options for Phase 3 include next-generation compressed air and various thermal or mechanical-based storage technologies. Also, storage in this phase might provide additional sources of value, such as transmission deferral and additional time-shifting of solar and wind generation to address diurnal mismatches of supply and demand. Our scenario analysis identified $100 \mathrm{GW}$ or more of potential opportunities for Phase 3 in the United States, in addition to the existing PSH that provides valuable capacity in several regions. Of note for both Phase 2 and 3 is a likely mix of configurations, with some stand-alone storage, but also a potentially significant fraction of storage deployments associated with hybrid plants, where storage can take advantage of tax credits, or shared capital and operating expenses. As in Phase 2, additional VRE, especially solar PV, could extend the storage potential of Phase 3, enabling contributions of VRE exceeding $50 \%$ on an annual basis.

Phase 4 is the most uncertain of our phases. It characterizes a possible future in which storage with durations from days to months is used to achieve very high levels of renewable energy (RE) in the power sector, or as part of multisector decarbonization. Technologies options in this space include production of liquid and gas fuels, which can be stored in large underground formations that enable extremely long-duration storage with very low loss rates. This low loss rate allows for seasonal shifting of RE supply, and generation of a carbon-free fuel for industrial processes and feedstocks. Phase 4 technologies are generally characterized by high power-related costs associated with fuel production and use but with very low duration-related costs. Thus, traditional metrics such as cost per kilowatt-hour of storage capacity are less useful, and when combined with the potential use of fuels for non-electric sector applications, makes comparison of Phase 4 technologies with other storage technologies more difficult. The potential opportunities for Phase 4 technologies measure in the hundreds of gigawatts in the United States, 
and these technologies could potentially address the residual demand that is very difficult or expensive to meet with RE resources and storage deployed in Phases 1-3.

Our four phases framework is intended to describe a plausible evolution of cost-competitive storage technologies, but more importantly, it identifies key elements needed for stakeholders to evaluate alternative pathways for both storage and other sources of system flexibility. Specifically, an improved characterization of various grid services needed, including capacity and duration, could help provide a deeper understanding of the tradeoffs between various technologies, and non-storage resources such as responsive demand. Such a characterization would help ensure the mix of flexibility technologies deployed is robust to an evolving a grid, which will ultimately determine the amount of storage and flexibility the power system will need. 


\section{Table of Contents}

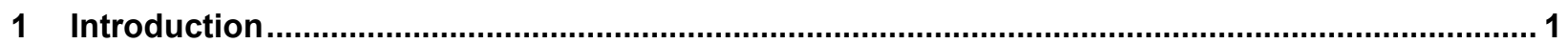

2 Historical (Pre-2010) Deployment of Energy Storage ............................................................... 3

3 Setting the Stage for Recent and Future Deployment: Valuation, Costs and Benefits................ 5

3.1 Storage Costs .............................................................................................. 5

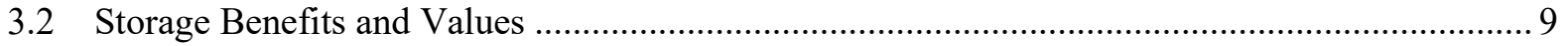

3.3 Storage Economic Performance Metrics ..............................................................

3.4 Competing Flexibility Technologies and Approaches .................................................. 10

4 Phase 1: Short-Duration Storage for Providing Operating Reserves ................................... 11

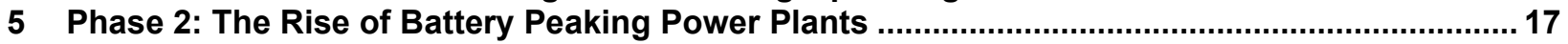

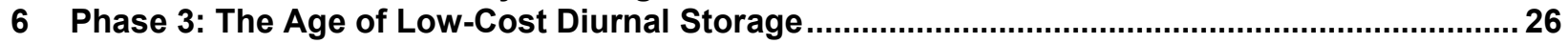

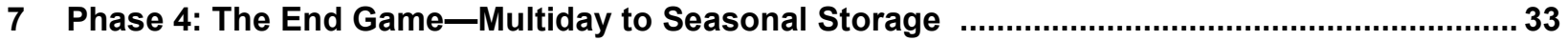

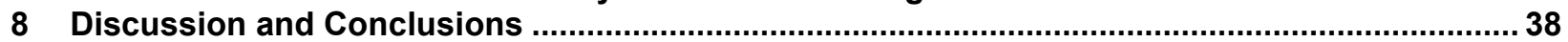

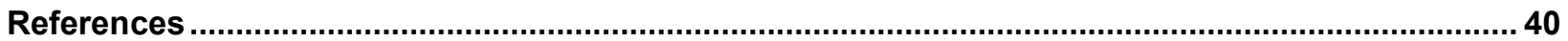




\section{List of Figures}

Figure 1. Cumulative electricity storage deployment, 1950-2010 ….................................................... 3

Figure 2. Power versus energy components in an energy storage power plant ...................................... 6

Figure 3. Simplified relationship between capital cost of energy storage and duration (7) ....................... 7

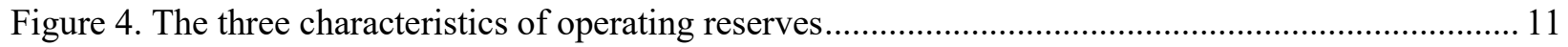

Figure 5. Example of the value of battery storage providing operating reserves..................................... 14

Figure 6. Current U.S. grid requirements for high-value operating reserve products potentially served by

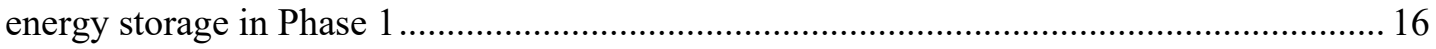

Figure 7. Value of storage providing capacity, assuming a 4-hour duration requirement and a $\$ 90 / \mathrm{kW}-\mathrm{yr}$

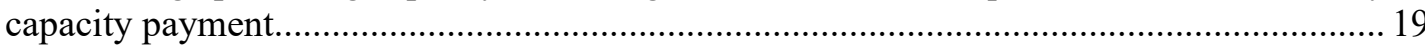

Figure 8. Example of the total and marginal value of energy time-shifting ........................................... 20

Figure 9. Example of the total and marginal value and B/C ratio of a battery storage system providing peaking capacity using battery costs from Figure 3 and assuming a 4-hour duration

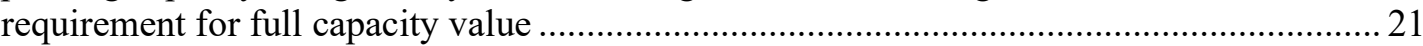

Figure 10. Simulated impact of increased 4-hour storage deployment on net load shape ........................23

Figure 11. Change in load shape on the day with peak demand in California (2013 simulated data)........ 24

Figure 12. The potential opportunity of Phase 2: National potential of 4-6 hour batteries with high

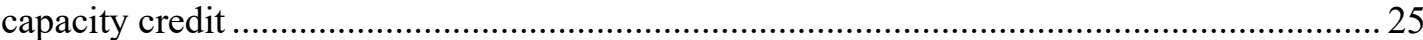

Figure 13. Example of longer-duration storage providing system capacity in California during the summer

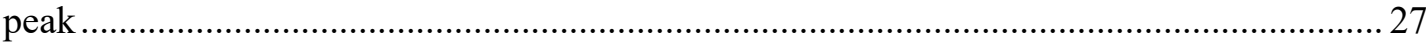

Figure 14. Annualized capacity value as a function of duration for different capacity credit duration

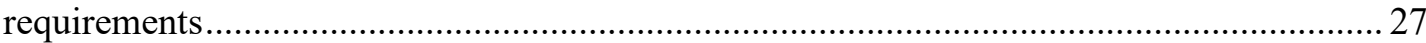

Figure 15. Availability of curtailed energy during a spring period showing length of curtailment events 29

Figure 16. Simulated flattened loads in ERCOT at 80\% RE 31

Figure 17. National opportunities for long-duration (up to 12-hour) storage providing capacity services in

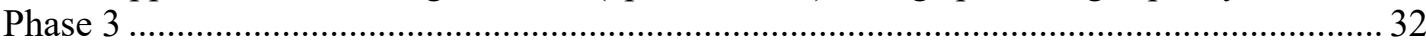

Figure 18. Chronological results of seasonal storage in a 99\% RE scenario ........................................... 34

Figure 19. Residual load duration curves at 90\% RE showing the need for significant firm capacity....... 36 Figure 20. Bounding the size of Phase 4 by estimating the national residual capacity requirements under $80 \%-90 \%$ RE scenarios

\section{List of Tables}

Table ES-1. Summary of the Four Phases of Storage Deployment ........................................................... vii

Table 1. Four Major Categories of Bulk Power System Storage Services .............................................. 9

Table 2. Phase 1 Storage Deployment for Provision of Operating Reserves, 2011-2019....................... 15

Table 3. Regional Energy Storage Duration Requirements ............................................................. 18

Table 4. Summary of the Four Phase Conceptual Framework …............................................................. 38 


\section{Introduction}

For the first century of the electric power system in the United States, electrical energy storage provided a small fraction (less than 3\%) of the total system capacity (1). But with declining costs and the promise of new storage technologies and increased deployment of variable renewable energy (VRE) resources, interest in the potential for large-scale deployment of energy storage is growing.

In a competitive and highly regulated industry, storage must provide cost-effective services that meet system needs. In this report, we describe a value proposition for energy storage that could result in cost-effective deployments, which could reach hundreds of gigawatts (GW) of installed capacity and result in a significant change in the nation's electric grid. Section 2 and 3 of this report set the stage for recent and future energy storage deployment in terms of valuation, costs and benefits. Sections 4-7 then describe a vision of future storage deployment following four phases:

- Phase 1: Short-Duration Storage for Providing Operating Reserves (Section 4)

- Phase 2: The Rise of Battery Peaking Power Plants (Section 5)

- Phase 3: The Age of Low-Cost Diurnal Storage (Section 6)

- Phase 4: The End Game: Multiday to Seasonal Storage (Section 7)

While we present four distinct phases, the boundaries between each phase will be somewhat indistinct, as described in subsequent sections. Each phase is described in terms of storage duration and the corresponding services provided. We discuss technical and market requirements, including an estimate of the potential deployment in each phase and how transition points might occur as market opportunities for shorter-duration storage become saturated and storage duration costs decline. ${ }^{2}$ We also demonstrate how the size of each phase (particularly Phases 2-4) are heavily influenced by VRE deployments that impact net load shapes.

The first of our four phases - the deployment of short-duration (under 1 hour) storage capacity for providing operating reserves - has actually been underway for nearly 10 years. The second phase, which has more recently begun in some locations is the deployment of battery peaking plants with 2-6 hours of duration. The third phase represents a transition to lower cost and potentially longer-duration storage that could include a range of technologies in various stages of commercial development. The final phase is very long duration (greater than 12 hours to seasonal) storage that potentially becomes economic under scenarios of extremely large-scale renewable energy (RE) deployment, including under scenarios of $100 \%$ RE grids or scenarios of certain technology breakthroughs.

\footnotetext{
${ }^{2}$ This concept of phases in the evolution of the power system is similar to that proposed by the International Energy Agency for renewables deployment (2). They describe six phases that are aligned with increased levels of variable RE deployment, and each phase requires a different set of measures to address the resulting variability and uncertainty of net load. This is somewhat similar to how our phases vary as increased storage (and RE) deployment create changes in net load and grid services needed.
} 
Our intention for this work is to consider the potential for large increases in energy storage deployment in the United States so that utilities, regulators, and developers can be better prepared for this deployment and can understand the need for careful analysis to ensure costoptimal deployment. This work also considers the changing role of storage as the grid evolves and the importance of storage as a capacity resource increases.

While we identify large potential opportunities for storage technologies based on currently monetizable services, actual deployment opportunities are highly uncertain, particularly for later phases (primarily Phase 3 and Phase 4), which may require new technologies with uncertain cost and performance trajectories. 


\section{Historical (Pre-2010) Deployment of Energy Storage}

Before the introduction of restructured electricity markets, which began largely in the early 2000s, the United States had about $23 \mathrm{GW}$ of electrical energy storage deployed, virtually all of it in the form of pumped storage hydropower (PSH) (1). This storage was built largely as an alternative to conventional fossil-fueled peaking capacity under the regime of least-cost planning by vertically integrated utilities (3). Many of these storage plants were planned and built in response to the prospect of very low cost baseload power being provided primarily by nuclear and coal plants but also in response to increasingly expensive sources of traditional peaking capacity such as steam plants burning high-cost oil and natural gas. Other motivations included restriction on the construction of gas-fired plants resulting from the Power Plant and Industrial Fuel Use Act of 1978. Pumped storage provided a means to increase the flexibility of baseload resources, enabling charging with off-peak energy and discharging during periods of higher demand, thus offsetting the need for (then) higher-cost oil- and gas-fired capacity.

Between 1960 and 1985, about $20 \mathrm{GW}$ of the $23 \mathrm{GW}$ of electrical energy storage capacity was built, often with long lead times that resulted in some limited deployment into the 1990s. Figure 1 shows the cumulative historical deployment of these pumped storage plants up to 2010, and also all other storage technologies (largely a single compressed-air energy storage facility completed in 1992).

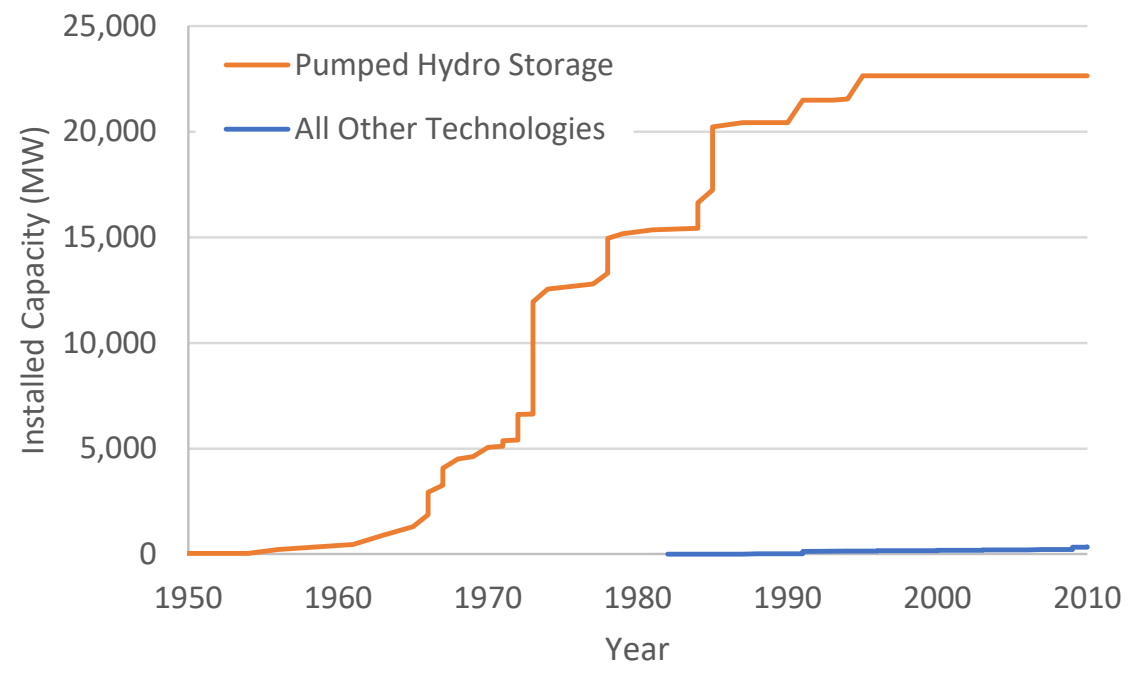

Figure 1. Cumulative electricity storage deployment, 1950-2010

The multidecade-long hiatus in significant storage deployment after the early 1990s can be attributed to a variety of factors, including the advent of more cost-effective gas turbines, repeal of the Power Plant and Industrial Fuel Use Act of 1978, and lower-cost natural gas. These factors resulted in the development of natural gas-fired power plants to provide peaking capacity and very limited storage deployment (of any type) between 1990 and 2010.

The existing PSH plants continue to provide firm capacity, energy time-shifting, and multiple operating reserves, and they are expected to continue providing these services for the foreseeable future, with their role adapting as the grid evolves, such as increasing use for integration of RE 
or grid black start capability $(4,5)$. Therefore, deployment of new storage in our four phases framework supplements the services already provided by existing pumped storage. In addition, upgrades to existing pumped storage plants are also possible, and they would improve efficiency and response time (6). Deployment of new, next-generation pumped storage is discussed in Section 6 (associated with Phase 3.) 


\section{Setting the Stage for Recent and Future Deployment: Valuation, Costs and Benefits}

New storage will be deployed based on its ability to potentially provide a cost-effective alternative or supplement to the various technologies that currently provide the host of services needed to maintain a reliable grid. Our four phases framework connects grid services with durations required to provide those services. The four phases reflect the evolving value proposition and cost structures for energy storage, starting with high-value, short-duration services, followed by storage progressively providing services that require longer durations, and in some cases, have lower value and thus require lower costs.

Assessing the economic performance of a new storage plant - whether it is a developer determining the plant's stand-alone economic performance or a vertically integrated utility comparing it to alternative resources - involves estimating the cost and benefits (or revenues) over the life of the project and comparing the associated economic performance with those of alternative resources or investment options. Example costs and benefits are discussed below to demonstrate the implications of the four phases framework.

\subsection{Storage Costs}

The cost of traditional power plants typically includes initial fixed capital costs, ongoing fixed costs, and a variety of variable costs, including fuel and operation and maintenance.

A major difference between the capital costs of storage and conventional plants is that storageunlike a conventional technology - has two components: power and energy. Because electricity is almost always stored in another form (e.g., potential energy of water, electrochemical bonds, or kinetic energy), power conversion equipment is required to convert electricity into this other form and then back again using pumps, power electronics, or other technologies. This process represents the power component of a storage plant and associated costs.

The energy component of storage is associated with the storage medium (e.g., water, chemicals, or rotating mass) and the container that holds the medium. Figure 2 illustrates these components (in a simplified manner) for several different storage technologies, with power-related components shown in red and energy components shown in yellow. For some technologies, such as hydrogen and flow batteries, there is a fairly clear distinction, with the power component being largely a stand-alone set of equipment, while the energy component consists of a storage tank or underground formation for the storage medium (hydrogen or electrolyte). For other batteries, such as Li-ion batteries, the design and construction of the battery module influences its power capacity, which somewhat reduces the absolute distinction between power and energy. 


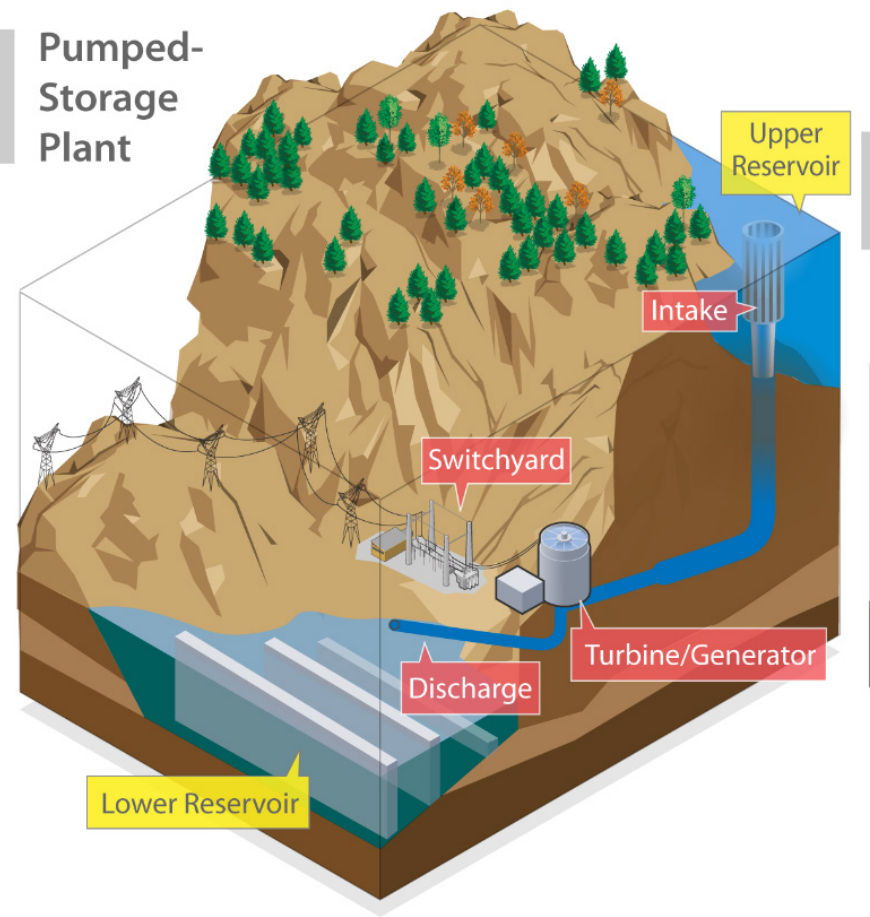

(a) Pumped storage hydro

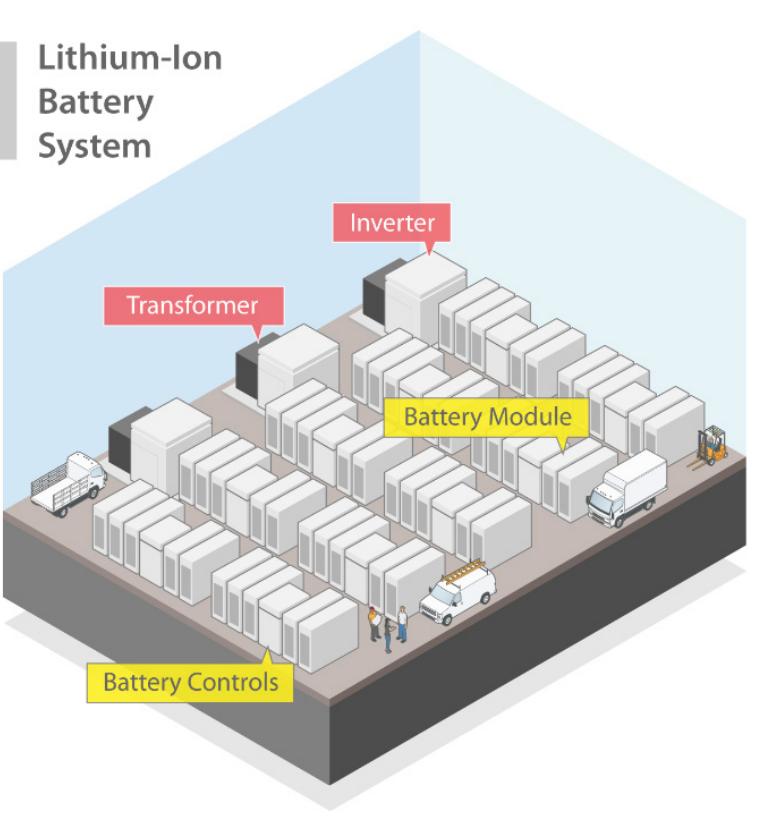

(b) Li-ion battery
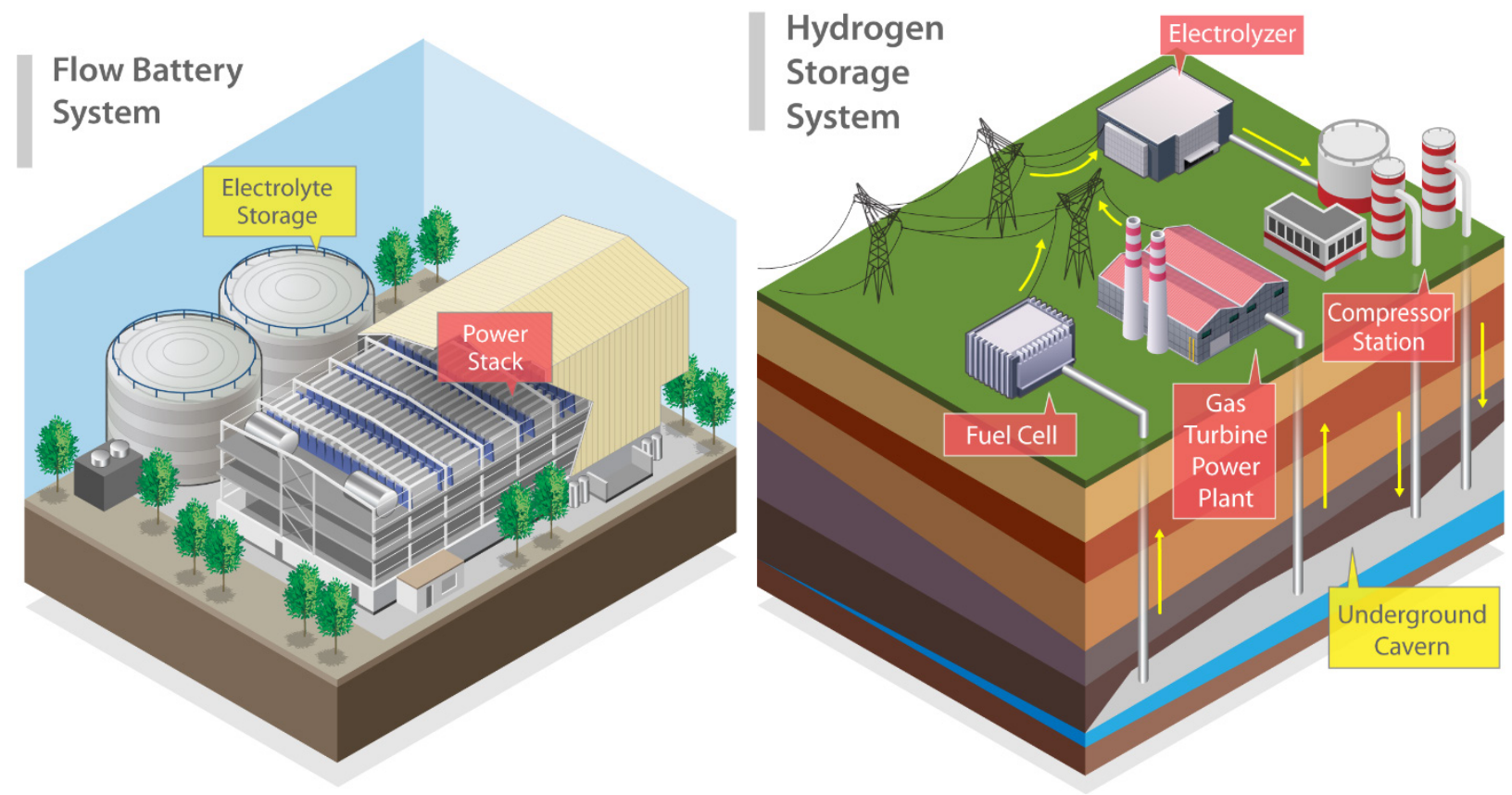

(c) Flow battery

(d) Hydrogen

Figure 2. Power versus energy components in an energy storage power plant

Power-related components are annotated in red and energy components in yellow. Images are not to scale 
Because storage plants have both a power component and an energy component, the cost of a storage power plant increases continuously as a function of duration for most technologies. Figure 3 illustrates the relationship between duration and cost for three types energy storage technologies using cost estimates from (7).

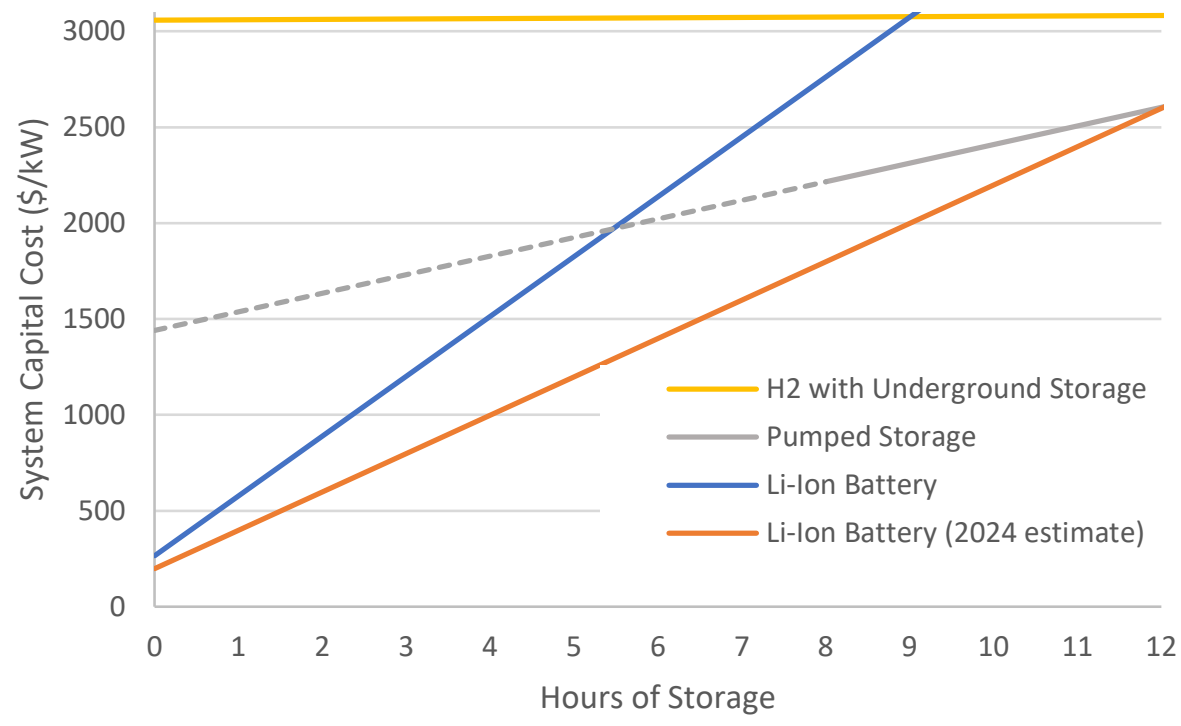

(a) Total capital cost

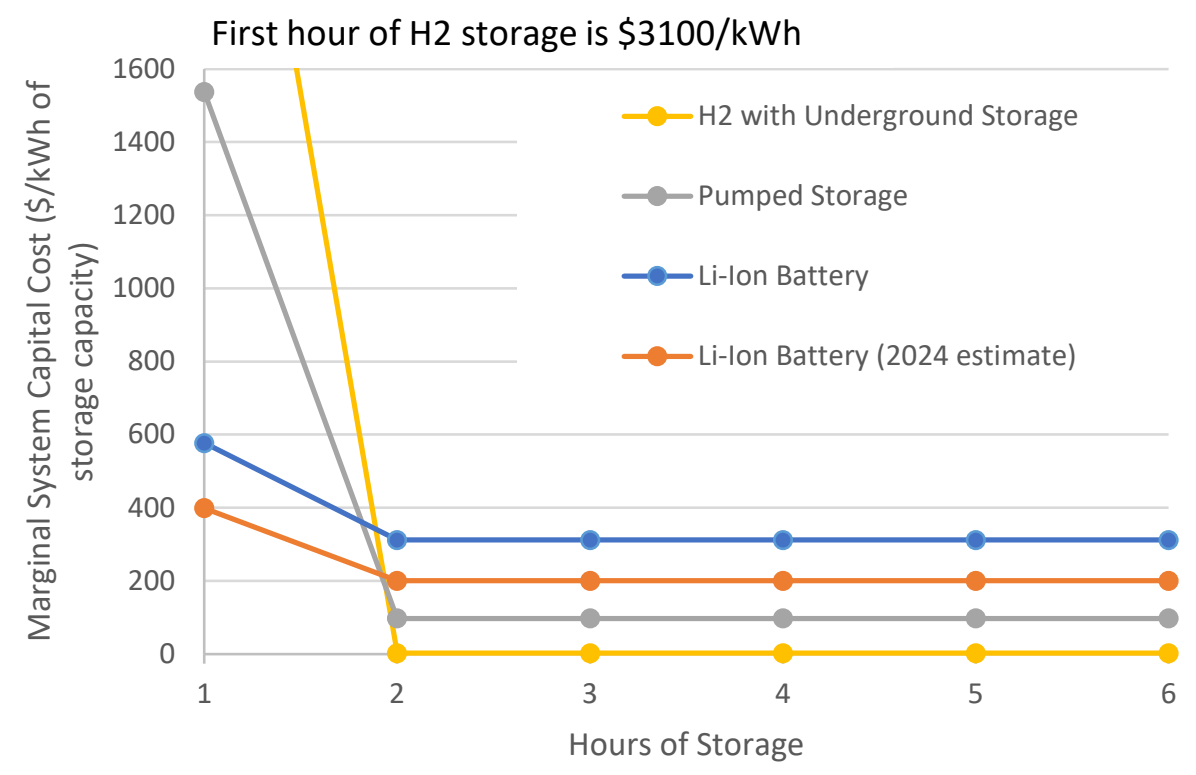

(b) Incremental capital cost

Figure 3. Simplified relationship between capital cost of energy storage and duration using 2020 cost estimates (7)

$$
\text { kW = kilowatt, } \mathrm{kWh}=\text { kilowatt-hour, } \mathrm{H} 2 \text { = hydrogen }
$$


Figure 3a shows estimated total capital cost of three different storage technologies, measured in dollars per kilowatt $(\$ / \mathrm{kW})$, which is the standard measure of power plant costs. ${ }^{3}$ The figure shows the initial power component associated with power conversion equipment, which could be thought of as building a storage plant with no energy storage capacity (duration), or only the power part of the plants illustrated in Figure 2. As duration is added, the costs increase at a rate that is assumed to be constant and is equal to the cost for each additional hour of storage duration (dollars per kilowatt-hour) multiplied by the number of hours. ${ }^{4}$ This is also reflected in the cost per incremental hour, shown in Figure 3b, which starts with the first hour and includes the power cost, and then each additional hour requires only the energy-related costs.

We use these three technologies to illustrate the important difference between energy- and power-related costs. For example, Li-ion batteries have a relatively low power-related cost but a high energy (duration) cost, which results in the highest rate of increase in capital cost as a function of duration. Our pumped storage curve represents a technology with higher powerrelated costs but a lower cost per unit of incremental energy. For pumped storage in particular, this curve is only illustrative, as pumped storage costs are typically site-specific and can leverage significant economies of scale for both power- and energy-related costs. This also means pumped storage typically has a declining incremental cost as a function of duration (which would produce a downward slope in Figure $3 \mathrm{~b}$ as opposed to the constant incremental value illustrated); so, the total system increase is not actually linear as shown in Figure 3a. For this reason, we include a dashed line to capture the considerable uncertainty around these cost assumptions, particularly as pumped storage historically is constructed with 8 or more hours of capacity. Finally, we include a boundary case of hydrogen storage with the highest power-related costs but that also uses an underground formation that assumes close to zero cost for additional duration after the initial development.

Figure 3 is simplified and used to demonstrate the basic relationships between storage duration and capital costs. This relationship will strongly influence the overall economic performance of storage technologies used for different applications; therefore, understanding the impact of duration on overall storage value is critical.

Figure 3 includes only the initial capital costs. The total life-cycle cost of storage technologies includes several other important components that vary by technology. Technologies with shorter calendar lives or higher cycling-introduced degradation will require more frequent replacement or refurbishment of key components. Variable operation and maintenance costs will also vary by technology, while round-trip efficiency impacts the cost of charging electricity needed to provide different services. These factors are considered when evaluating the total economic performance, as discussed in Section 3.3.

\footnotetext{
${ }^{3}$ Note that all costs are measured in terms of the AC rating, as the grid uses AC power.

${ }^{4}$ Ideally, this measurement represents usable energy, after accounting for state of charge limitations, conversion to $\mathrm{AC}$, and other factors.
} 


\subsection{Storage Benefits and Values}

Storage can provide an array of services that can largely be represented by four general classes (Table 1) that capture over $95 \%$ of the costs of operating the bulk power system. ${ }^{5}$

Table 1. Four Major Categories of Bulk Power System Storage Services

\begin{tabular}{ll}
\hline Service & Description \\
\hline Capacity & Firm capacity \\
\hline Energy & Energy shifting/dispatch efficiency/avoided curtailment \\
\hline Transmission & Avoided capacity, congestion relief \\
\hline Ancillary services & Operating reserves, voltage support \\
\hline
\end{tabular}

Note that Table 1 does not explicitly list RE-specific applications, such as "renewable firming" or "renewable time-shifting." These applications are specific cases of the more general applications listed and are therefore already captured in Table 1.

Likewise, Table 1 captures some applications that can be provided by behind-the-meter storage. For example, firm capacity and energy shifting value is reflected in tariffs by demand charges and time-of-use rates. However, the table does not include several additional values provided by distribution- or customer-sited storage, including avoided upgrades and local reliability and resiliency. We focus here exclusively on utility-scale storage; other analyses within the Storage Futures Study examine the potential value, costs, and potential adoption of behind-the-meter storage.

\subsection{Storage Economic Performance Metrics}

The simplest economic performance metric commonly applied to generation technologies is the levelized cost of energy (LCOE). It measures the delivered cost of energy, including both fixed and variable costs, and it also includes the impact of financing, expected life, and expected annual energy production. A similar metric is the levelized cost of storage (LCOS). It includes all fixed and variable cost components over the life of the storage plant, including charging energy and the impact of round-trip efficiency. The limitations of LCOE and LCOS as a standalone performance metrics are widely documented, but the most obvious is that they provide no indication of the value of the energy or other services potentially provided (10). This is particularly problematic when comparing storage technologies that provide fundamentally different services (e.g., short-duration storage that provides only operating reserves) to longerduration technologies (e.g., pumped storage that provide multiple services, including firm capacity, time-shifting, and operating reserves).

To properly evaluate the economic performance of storage, metrics that consider both costs and benefits must be used. The actual metric used depends on the perspective of the owner or operator (which may not be the same entity). Vertically integrated utilities and other regulated entities typically use a least-cost planning approach, which is sometimes referred to as integrated

\footnotetext{
${ }^{5}$ By the bulk power system, we mean the high voltage transmission system and generators but not the distribution network. The 95\% value is derived from data in PJM (8) and ISO-NE (9).
} 
resource planning (11). This approach compares various resources over an extended (i.e., multidecade) period to derive a least-cost mix while considering reliability and various policy constraints. While the final performance metric is expressed in terms of a cost (e.g., a net present cost or even an LCOE of the entire system), the value of various services provided by the entire system is embedded in this cost. For example, storage acting as a peaking plant can reduce operating costs across the generation fleet, and this benefit is reflected in a reduced system cost.

A second approach — which an independent power producer might use - is to evaluate the economic performance of storage in isolation, and to then compare its life-cycle costs to lifecycle revenue to determine whether this results in a satisfactory rate of return or other economic performance metric. This second approach can be easier to calculate, and we use it in several examples in this work to illustrate the cost-competitiveness of batteries for several applications.

Evaluating the economic competitiveness of storage in either a least-cost portfolio or as a standalone investment requires an additional analysis element: determination of the optimal duration of storage. This analysis is unique to storage and compares the incremental costs of storage duration to the incremental benefits of the added duration, thus ensuring the value of adding more hours exceeds the costs. This type of evaluation of duration drives the markets for energy storage, and in the following sections, we use the framework of the four phases to examine the relationships of storage duration, value, and applications.

\subsection{Competing Flexibility Technologies and Approaches}

This report focuses on economic drivers of new storage deployment. In many cases, such as the use of storage to provide peaking capacity, storage is compared to a traditional gas-fired generator. However, the flexibility and value that storage provides can also be supplied by other competing technologies, including demand response, managed charging of electric vehicles, and other sources of flexible supply or demand. The framework presented here could be applied to other approaches to provide grid flexibility and could demonstrate variations in the competitiveness or storage or the overall market potential. 


\section{Phase 1: Short-Duration Storage for Providing Operating Reserves}

After the minimal deployment of storage that occurred after the 1980s, interest in storage was renewed in the early 2000 s with the convergence of several events. One was the creation of wholesale markets. These markets eventually included several operating reserve products that provided storage an opportunity to directly compete and demonstrate its potential value compared to resources that have traditionally provided these services (12).

While operating reserves consist of numerous services and market products, they all represent the ability of a generator or aggregated set of generators to increase output (provide "upward" reserves) or decrease output (provide "downward" reserves) (13). These reserves are provided in response to random variations in supply and demand at various time scales. The distinctions between different reserve services can be characterized by three factors:

- How much reflects the quantity of power potentially needed by the system, or how much headroom is needed from the set of plants providing this service; this is measured in power capacity (megawatts [MW]).

- How fast reflects the response rate needed or how quickly the set of plants providing the services are required to move from one setpoint to another ( $\mathrm{MW} / \mathrm{second})$ and is a combination of the time needed to initiate a response to the reserve event and ramp rate.

- How long is the duration for which the plants must hold the new output, and for an energy storage device, represents the amount of stored energy (megawatt-hours [MWh]).

The application of these three factors to a single plant is illustrated in Figure 4, which shows the output of a generator that is operating below maximum output and able to provide some reserve capacity based on its operating limits.

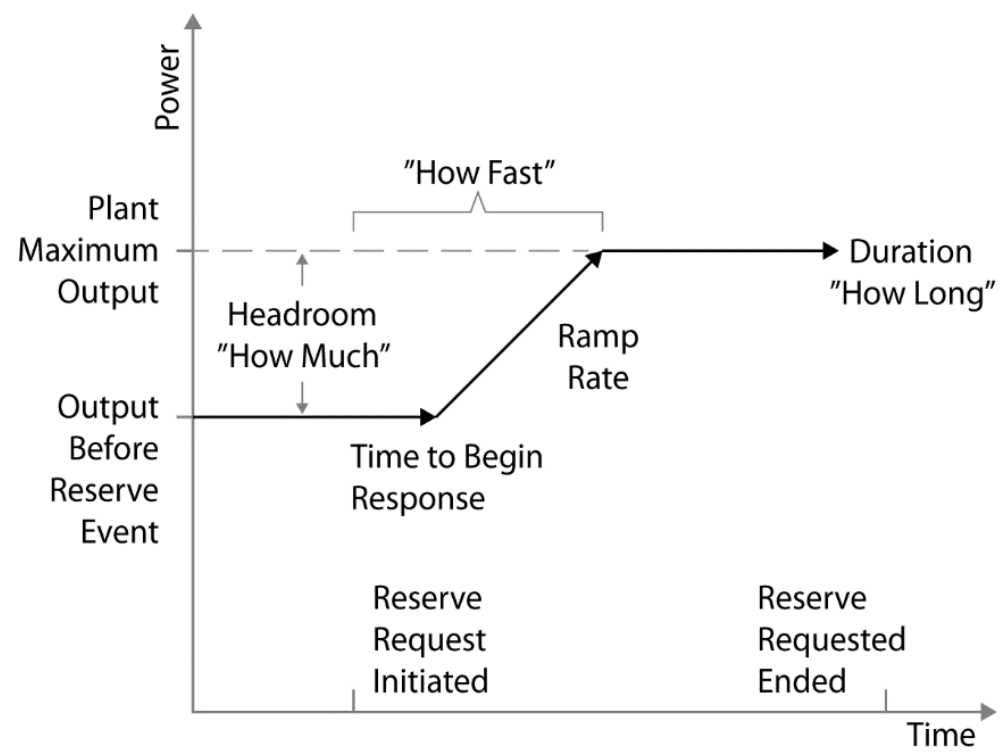

Figure 4. The three characteristics of operating reserves 
Though specific operating reserve products have different names depending on the region, we focus here on two major classes that exist in all market regions in the United States and which offer higher value:

- Spinning contingency reserves are used to respond rapidly to address the failure of large power plants or associated transmission lines.

- Regulating reserves are used to address smaller, random variations in supply or demand. ${ }^{6}$

We do not consider non-spinning or supplemental reserves, which are slower to respond and require a long-duration response of multiple hours.

In brief, "how much" of each reserve produce is required is determined by each balancing area. ${ }^{7}$ How much of this can be provided by any individual storage asset is determined by its power capacity and operating state, meaning it must operate at less than full output (holding headroom) and hold sufficient energy to respond to a reserve call or event.

Each balancing area also establishes rules for the response rate ("how fast") required for generators to participate in the provision of operating reserves. For example, an operator might require a generator to increase output in 10 minutes for the provision of spinning contingency reserves.

Rules also establish the length of time a unit must be held at the increased output, typically in the range of 15-30 minutes. As an example, spinning contingency markets may require a resource providing this service to hold output for at least 30 minutes (reflecting the time needed to bring up additional generation capacity) (15). For a 1-MW storage device to be able to provide this service, it would need to have 30 minutes of discharge capacity or $0.5 \mathrm{MWh}$ of stored energy. A device with less energy capacity (duration) could still provide this service, but with a lower power rating. For example, a 1-MW device with 15 minutes of capacity ( $0.25 \mathrm{MWh})$ would need to discharge at $0.5 \mathrm{MW}$ to supply power for the 30-minute interval.

\section{Value of Phase 1 Services}

Historical market values can be used to estimate an approximate value for energy storage providing various services. Prices for operating reserves are often measured in units of capacity available during 1 hour (MW-hr). This is not a unit of energy - it represents capacity that is available for a response over a period of time. ${ }^{8} \mathrm{~A}$ facility providing spinning contingency reserves is paid for this provision even if there are no calls for providing energy; more simply stated, the plant is paid for doing nothing other than being ready to respond and then responding if called to do so. The average spinning contingency reserves market prices in 2019 ranged from

\footnotetext{
${ }^{6}$ Though regulating reserves are sometimes referred to as "frequency regulation," the North American Electric Reliability Corporation glossary defines frequency regulation to include both governor response (frequency response) and the service described in this section (14). To avoid potential confusion, we use the term regulating reserves.

${ }^{7}$ The balancing area is the entity responsible for balancing supply and demand, including the provision of operating reserves. Depending on location, this can be a market operator (independent system operator/regional transmission organization) or a vertically integrated utility.

${ }^{8}$ Some regions use cost per $\mathrm{kW}$-month. This is also is similar to how payments in capacity markets may be measured in $\mathrm{kW}-\mathrm{yr}$, or the provision of $1 \mathrm{~kW}$ of capacity for a 1-year period.
} 
\$3/MW-hr to \$27/MW-hr, with a national weighted average of about \$11/MW-hr. A storage plant providing contingency reserves would essentially "idle" in a charged state, waiting for a response, and then be paid for the whole time. When called, the plant would then discharge until the end of the event and then recharge as soon as possible so that it could return to a charged state and provide reserves again.

Regulating reserves are more complicated. Unlike contingency reserves, which are rarely used, provision of regulating reserves requires a unit to change output fairly frequently in response to small, random variations in demand (16). ${ }^{9}$ A storage plant providing regulating reserves would sit at a condition with a high state of charge, but it would continuously increase and decrease output in response to grid needs. This frequent, shallow cycling would incur additional costs that are due to battery degradation, as well as costs for make-up energy to compensate for losses associated with the potential substantial energy throughput. However, prices for regulating reserves are typically higher than those for contingency reserves; average 2019 regulating reserve prices in market regions ranged from about \$6/MW-hr to \$32/MW-hr for combined up and down reserves, and the weighted national average was about $\$ 15 / \mathrm{MW}-\mathrm{hr} .{ }^{10} \mathrm{This}$ capacityrelated payment is often supplemented by a payment associated with increasing or decreasing output. $^{11}$

In either case, the device could provide operating reserve services close to $100 \%$ of the time, limited mainly by periodic maintenance. Such provision of services nearly $100 \%$ of the time has enabled a cost-effective entry point for energy storage, even before recent cost declines.

A key aspect of these services is that once the minimum duration requirement ("how long") is met, there is no additional value for additional duration (stored energy) for a given market service. If the duration requirement were 30 minutes, a 1-MW battery with 1 hour of storage would receive no additional value compared to a 1-MW battery with 30 minutes of storage. Figure 5a shows a specific example of the value of a device providing spinning reserves under the Arizona Public Service tariff of $\$ 6.26 / \mathrm{kW}$-month $(\$ 75 / \mathrm{kW}-\mathrm{yr})^{12}$ for spinning reserves and a 30-minute requirement. A 10-minute battery would need to be derated to one-third of its capacity to provide 30 minutes of service, and therefore this battery would receive about $\$ 25 / \mathrm{kW}$-year (with $100 \%$ availability). Each dot on the "marginal" curve shows the value of an incremental 10 minutes of storage. The total value increases as storage duration is added until the battery reaches 30 minutes of duration, at which point the value of adding additional duration for this service is zero.

\footnotetext{
${ }^{9}$ As a result, a fourth parameter associated with operating reserves might be described as "how often" or the frequency at which a reserve service is called. It ranges from to a few times month for spinning contingency reserves to nearly continuously for regulating reserves.

${ }^{10}$ Higher prices for regulating reserves partially reflect wear and tear and degraded performance of the thermal plants that often provide these services. Data includes CAISO, ERCOT, ISO-NE, MISO, NYISO, PJM, and SPP (13).

${ }^{11}$ This is sometimes referred to as a mileage payment. In addition, regulating reserve prices may vary based on the speed and accuracy of a plant following a regulations signal, with an example being PJM, which has two regulating reserve markets separated by speed of response (13).

12 "Arizona Public Service Company Pro Forma Open Access Transmission Tariff," http:/www.oatioasis.com/AZPS/AZPSdocs/APS OATT Volume 2 20170601.pdf
} 


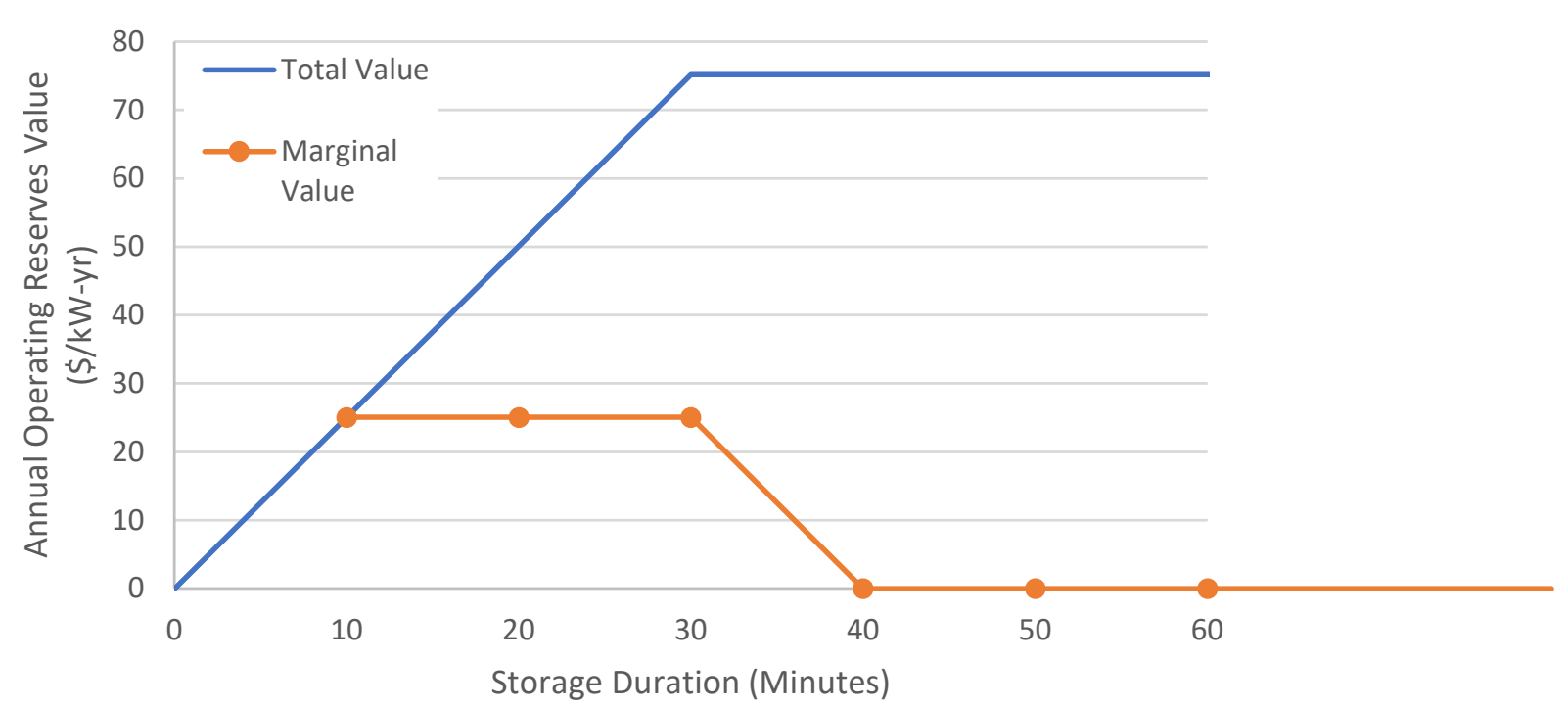

(a) Example of the total and marginal value of spinning reserves assuming tariff value of $\$ 75 / \mathrm{kW}-\mathrm{yr}$

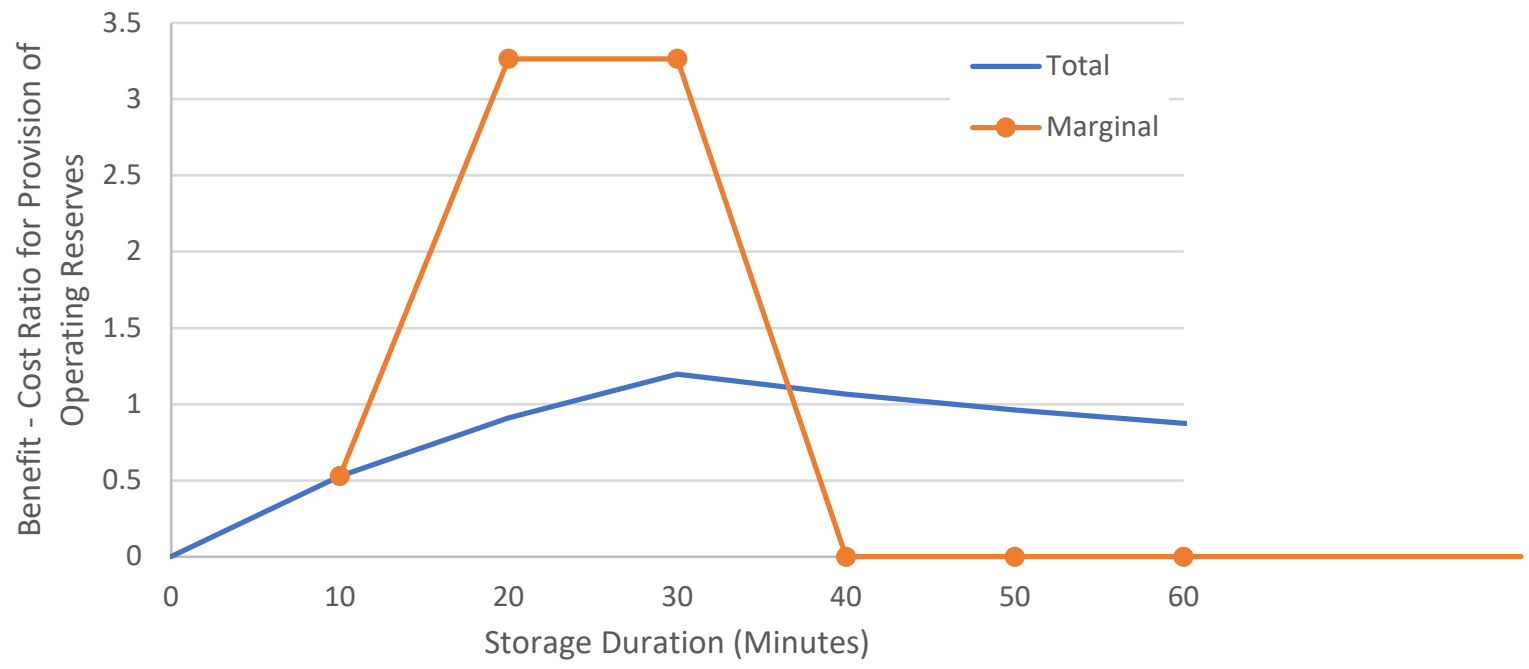

(b) Example of total and marginal B/C ratio assuming $90 \%$ battery availabliity and 2020 Li-lon cost estimates

Figure 5. Example of the value of battery storage providing operating reserves

Figure $5 \mathrm{~b}$ shows the total and marginal benefit-cost $(\mathrm{B} / \mathrm{C})$ ratios for a Li-ion battery providing this service, assuming 2020 battery cost estimates from Figure 3 (7) and 90\% device availability. The figure shows that because of the high initial cost, a 10 -minute device has a $\mathrm{B} / \mathrm{C}$ ratio of less than one. However, the $\mathrm{B} / \mathrm{C}$ ratio of adding a second 10 minutes is much higher, as it is considering the incremental benefits of just the additional energy. Adding a third 10 minutes of duration (for a total of 30 minutes) maximizes the $\mathrm{B} / \mathrm{C}$ ratio of project as a whole. Adding another 10 minutes to the project (to a total of 40 minutes) would still provide a $\mathrm{B} / \mathrm{C}$ ratio of greater than 1 for the project as a whole even though the marginal B/C ratio would be zero. So, examining a 40-minute project in isolation could appear to be a reasonable investment. However, increasing the duration from 30 to 40 minutes actually lowers the overall return on the project and would actually result in a nonoptimal investment, which is also reflected in the zero marginal value curve after 30 minutes. This change in marginal value is why it is critical to compare marginal costs and benefits as a function of duration. 
The ability of storage to provide cost-competitive operating reserves has resulted in significant deployments of energy storage in the United States of 1 hour or less (Table 2). ${ }^{13}$

Table 2. Phase 1 Utility-Scale (>0.5 MW) Storage Deployment with 1 hour or less capacity, 20112019

\begin{tabular}{lc}
\hline Region & Deployment (MW) \\
\hline Alaska \& Hawaii & 27 \\
California & 139 \\
Non-CAISO Western Interconnection & 29 \\
Texas & 108 \\
PJM & 182 \\
New York \& New England & 66 \\
Other Regions in the Eastern Interconnection & 171 \\
\hline Total & $\mathbf{7 2 1}$ \\
\hline
\end{tabular}

The capacity in Table 2 includes $656 \mathrm{MW}$ of Li-ion batteries, $47 \mathrm{MW}$ of flywheels, and $18 \mathrm{MW}$ of other battery types.

\section{Limits to Phase 1: Total Reserve Requirements}

Phase 1 is limited by the total amount of high-value operating reserves needed in the U.S. power system, as summarized in Figure $6 .{ }^{14}$ Regulating reserves requirements are driven by the size of normal variability in net load, ${ }^{15}$ and contingency reserves are driven by the size of the largest expected power plant or transmission line failure in each region. The total requirement for these two services in the conterminous United States is about $18 \mathrm{GW}$; for comparison, peak demand is more than $600 \mathrm{GW}$. This means these markets have the potential to quickly saturate. ${ }^{16}$

Beyond existing operating reserve markets, monetization of existing frequency response requirements could add to the size (cumulative deployment of storage) of Phase 1. Frequency response, which is the ability of generators to respond rapidly and automatically to changes in frequency, is typically provided by generators equipped with governors. This is currently a market (i.e., a compensated) service only in the ERCOT region, but interest in a frequency response market is growing in other regions (13). Estimating the potential value of frequency response is difficult; regulating reserves market prices may be a reasonable lower bound proxy given the higher response rate needed for frequency response. However, like other reserve types described above, the total potential market is limited, with the total frequency response

\footnotetext{
${ }^{13}$ Data from EIA Form 860 for the year 2019. https://www.eia.gov/electricity/data/eia860/

${ }^{14}$ Data are derived from sources described in (13). For the requirement in nonmarket regions, we multiply the percentage requirement of a large utility in that region by the total peak demand of the larger region in which it is located. This means we use the requirements of a single utility as the proxy for the larger region as a whole.

15 This loosely represents the largest very rapid and unpredictable change in either load or VRE that occurs in a few minutes. This is typically small (a few percent), as most changes occur over longer timescales (16).

16 The chart in Figure 6 does not include non-spinning or replacement reserves, which may have multihour requirements and could potentially be served by storage in Phase 2 or beyond. The value of these services is historically much lower than the reservices considered here (13).
} 
requirement in the entire United States being about 8.2 GW (13). Overall, this total results in a technical potential of short-duration operating reserves of less than $26 \mathrm{GW}$ (Figure 6), with an economic opportunity for storage in Phase 1 likely being substantially less than this, particularly with competition from demand response including controlled EV charging, and existing PSH.

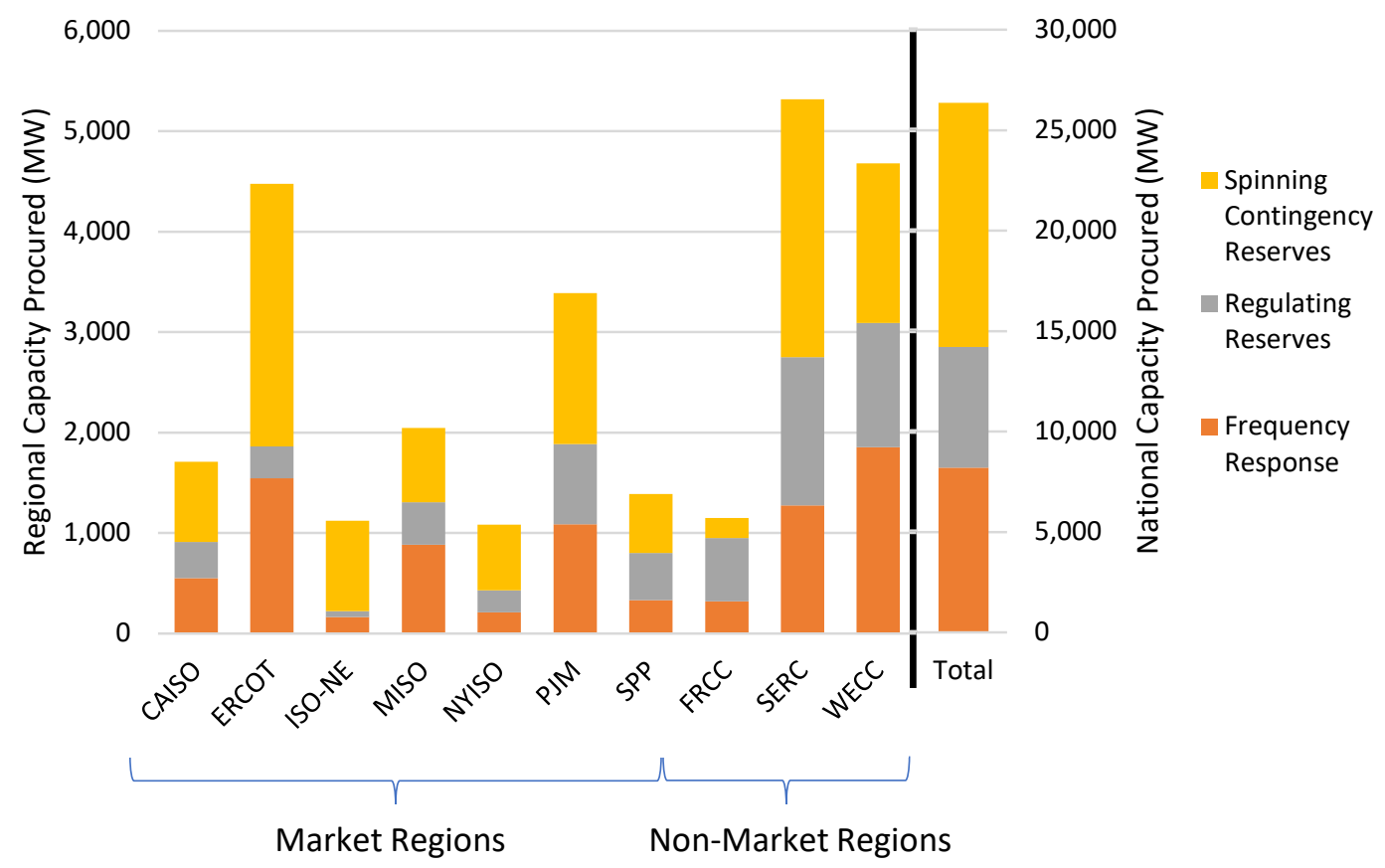

Figure 6. Current U.S. grid requirements for high-value operating reserve products potentially served by energy storage in Phase 1

Two additional factors could extend Phase 1. The first is additional market products, including a flexibility/ramping reserve product that has been created to address additional variability and uncertainty in the minutes-and-beyond time scales resulting from VRE deployment (13). This product has been introduced in a limited number of regions, and it typically requires a slower response rate (i.e., lower ramp rate) and longer duration (i.e., the resource holding output for longer) than regulating reserves.

The second factor that could extend Phase 1 is potential growth in regulating reserves that may result from increased deployment of VRE resources. However, several studies have found that much of the increase in variability occurs in time scales in the minutes-or-longer time scales (17, 18), and it may drive the creation and use of a flexible ramping reserve, as opposed to very large increases in regulating reserves. ${ }^{17}$ So overall, there is no clear evidence for a very large growth in operating reserve requirements as a result of large VRE deployments. Overall, though it is limited, Phase 1 represents an important entry point for storage, particularly in regions with little prior storage deployment and for services where storage can offer higher value.

\footnotetext{
${ }^{17}$ Deployment of VRE resources is unlikely to affect the requirements for contingency reserves and frequency response, where requirements are typically set based on the sizes of the largest likely system failures (13).
} 


\section{Phase 2: The Rise of Battery Peaking Power Plants}

As Phase 1 operating reserve markets saturate and declining battery prices create new opportunities, we transition to Phase 2: the deployment of batteries with about 2-6 hours of duration for providing peaking capacity. Peaking capacity is used to meet short periods of peak demand on hot summer days, or in some locations, in periods of extreme cold. Peaking capacity is typically provided by simple-cycle gas turbines, older gas steam plants, or internal-combustion generators (1). However, the continued decline in the costs of Li-ion batteries has increased their competitiveness over traditional sources, and Phase 2 has already begun in some locations (19).

In Phase 1, we consider short-duration storage providing only a single service because of the power constraints of the battery. This means that for a battery providing upward reserves, the entire power capacity of the battery is dedicated to the possibility of needing to increase output. Given the continuous need for this capacity when providing operating reserves, even if additional energy capacity (duration) were added, this duration would be unable to be used for other services as long as the device is providing operating reserves. As a result, it is difficult for devices aimed primarily at providing operating reserves to provide additional services.

Alternatively, a battery peaking plant typically provides multiple services, including provision of physical capacity (capacity credit), the value of energy time-shifting, and operating reserves during certain periods. A battery peaking plant can provide both capacity and energy shifting services simultaneously because the periods of highest prices (when the battery will discharge to maximize revenue or minimize system costs) are very highly correlated to periods of highest demand when the system needs reliable capacity (20). Periods of low prices (when the battery will charge) are also periods of low demand, and therefore when large amounts of spare capacity are available and the risk of an outage is low. Therefore, these two services - capacity and timeshifting - do not double count either the energy or power capacity of the battery and can be "stacked." 18

A multihour battery could also provide reserves in addition to capacity and energy shifting. When a battery is charging, it can provide upward reserves, as long as the battery has charged enough to meet the reserve duration requirement and has reserved sufficient energy to meet its capacity obligation. It can also provide upward reserves while "idle" in the period between charge and discharge.

As a result, there can be considerable overlap of Phase 1 and Phase 2, when batteries deployed in Phase 2 also provide operating reserves for additional revenue. At low enough storage costs, some regions may largely skip Phase 1 by using 2-hour to 6-hour devices to provide energy, capacity, and operating reserves. However, the same considerations of market saturation apply, particularly as batteries deployed in Phase 1 may reduce overall reserve prices. Therefore, we focus on the value of peaking capacity as the primary driver of the transition to Phase 2 , though

\footnotetext{
${ }^{18}$ The concept of combining multiple services, or "value stacking" is not unique to storage, and many generation resources provide multiple service and thus inherently value stack, although this term is seldom used when talking about traditional generation capacity.
} 
we acknowledge the potential for some "extra" value associated the provision of reserves as a secondary application.

\section{Evaluating the Cost-Competitiveness of Battery Peaking Plants}

If operating reserves are ignored, a battery peaking plant will obtain two sources of value (or revenue): capacity value and energy value.

Capacity value is the monetary value associated with providing physical capacity. The ability of this capacity to be available when needed is a critical component of this value. This is reflected in a generator's capacity credit, which is defined as the fraction of the generator's installed capacity that could reliably be used to meet peak demand ${ }^{19}$ (or offset conventional capacity), which is typically measured as a value (e.g., kilowatts) or a percentage of nameplate rating (21). ${ }^{20}$

Only recently has there been any significant effort to evaluate the capacity credit of energy storage. Analysis of the capacity credit of storage is important, as it determines the storage duration required to provide the same level of reliable services as traditional resources. In most regions of the United States, determination of both the need for new capacity and the capacity credit applied to new resources is established by some combination of state and market regulators as well as the local market operator.

In 2018, the Federal Energy Regulatory Commission issued Order 84,1 which includes the requirement that all independent system operators and regional transmission organizations under the commission's jurisdiction establish duration requirements for a device to receive full capacity or resource adequacy credit, as listed in Table 3 (23).

Table 3. Regional Energy Storage Duration Requirements

\begin{tabular}{lc}
\hline $\begin{array}{l}\text { Market } \\
\text { Operator }\end{array}$ & $\begin{array}{c}\text { Duration Minimum } \\
\text { (hours) }\end{array}$ \\
\hline ISO-NE & 2 \\
CAISO & 4 \\
NYISO & 4 \\
SPP & 4 \\
MISO & 4 \\
PJM $^{21}$ & 10 \\
\hline
\end{tabular}

Outside PJM, all regions have adopted a requirement of 4 hours or less, and analysis has demonstrated high capacity credit for 4-hour storage in several of these regions (23). However,

\footnotetext{
${ }^{19}$ More accurately stated, capacity credit analysis assesses the probability of a plant being available during periods of demand, which is typically during hot summer afternoons throughout most of the United States.

${ }^{20}$ Following Mills and Wiser (2012) (22), we use the term "capacity credit" to represent physical capacity, and we use the term "capacity value" to represent the monetary value of this capacity.

${ }^{21} \mathrm{PJM}$ is in the process of updating this value based on an effective load carrying capability calculation. ("PJM Interconnection L.L.C., Docket No. ER21-278-000 Effective Load Carrying Capability Construct," PJM, October 30, 2020, https:/www.pjm.com/directory/etariff/FercDockets/5832/20201030-er21-278-000.pdf.)
} 
analysis is ongoing, and there is some disagreement over the requirements in some regions (24); as we demonstrate later in this section, these duration requirements strongly impact the costcompetitiveness of energy storage.

The duration requirements in Table 3 (page 18) are used for planning purposes and for compensation in capacity markets or resource adequacy capacity contracts. As a result, a battery with 4 hours of capacity serving load could be compensated for providing capacity at the same rate as a traditional combustion turbine (on a dollars-per-kilowatt basis). ${ }^{22}$ Alternatively, a 3hour battery could be derated and receive three-quarters of the capacity payment. Thus, the capacity value of a storage resource as a function of duration has a shape like that in Figure 7. It shows the total and marginal value of capacity, assuming a 4-hour duration requirement, and an annualized capacity value of $\$ 90 / \mathrm{kW}-\mathrm{yr}{ }^{23}$

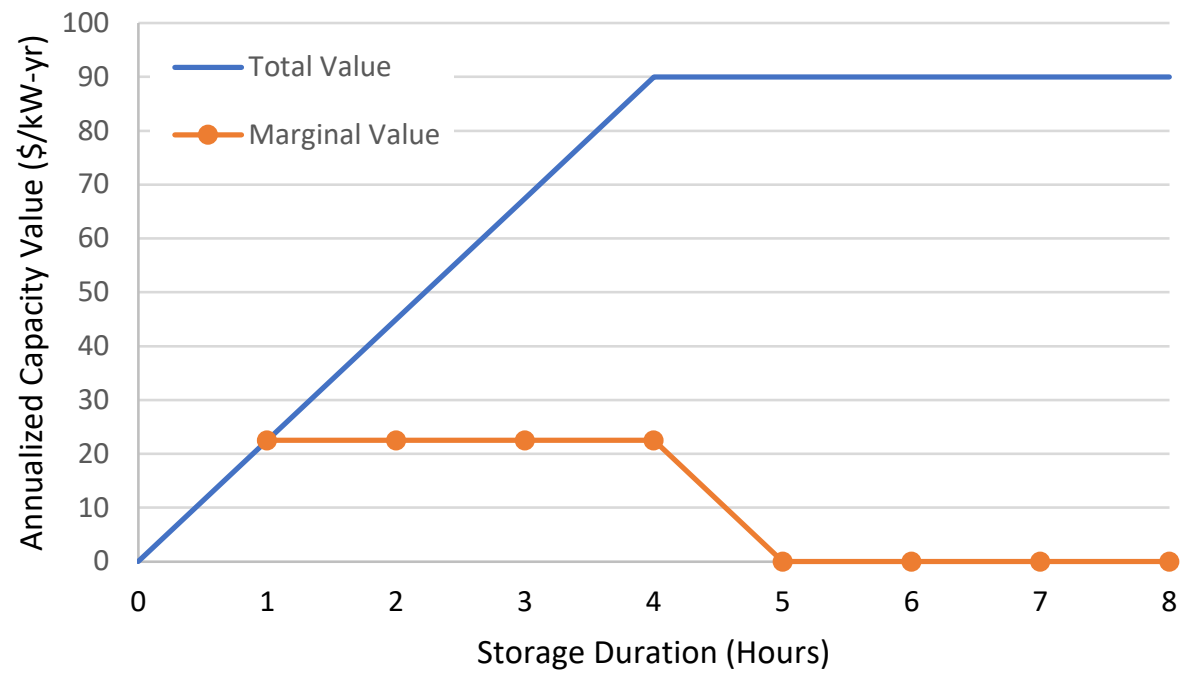

Figure 7. Value of storage providing capacity, assuming a 4-hour duration requirement and a $\$ 90 / \mathrm{kW}$-yr capacity payment

Of note in Figure 7 is that the capacity value as a function of duration increases only up to the duration requirement established by the market operator or regulator; a 6-hour battery receives no more value or revenue than a 4-hour battery for this particular service in this example. The figure also represents a system where new capacity is actually needed. In locations with sufficient capacity, the value of additional capacity can be very low, as reflected in low capacity prices in markets that approach or exceed reliability planning standards. As a result, battery storage or other sources of peaking capacity will not necessarily be cost-competitive in the near term until there is an increase in demand or sufficient retirement of existing capacity resulting in a need for new capacity.

\footnotetext{
22 This is simplified, as it assumes the two resources have identical outage rates.

${ }^{23}$ This value is roughly equal to the estimated net cost of a new entrant for a peaking combustion turbine in MISO and PJM in $2020(25,26)$. It is important to note that this value is higher than many historical capacity prices and reflects oversupply conditions.
} 
In addition to capacity, Figure 8 shows the annual value of energy shifting using an example of a hypothetical storage device dispatched into two wholesale market regions using 2019 data. $^{24}$ While the absolute value varies considerably depending on location and factors such as transmission constraints, the general trend in value as a function of duration is similar. The first hour of storage has the highest value, as it is arbitraging the largest spread in market prices. This incremental value declines rapidly as diurnal price spreads decrease, approaching — but not reaching - zero beyond about 10 hours of capacity as the diurnal variability in prices is completely arbitraged.

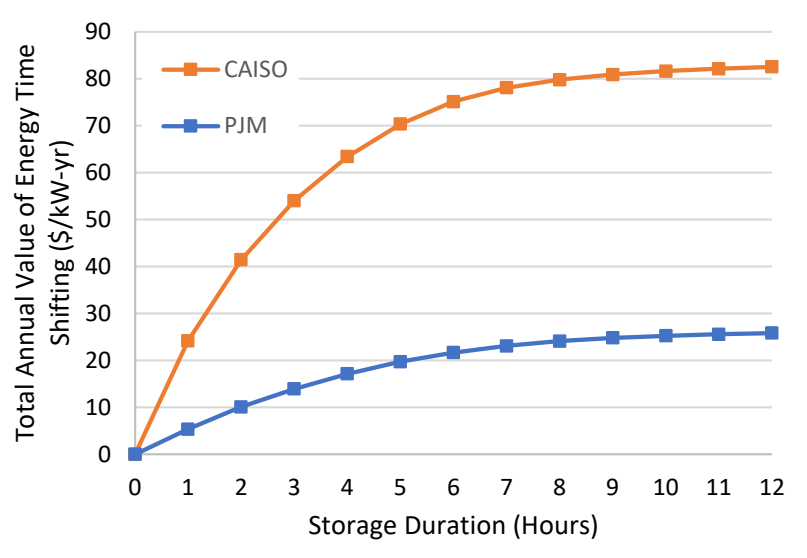

(a) Total value

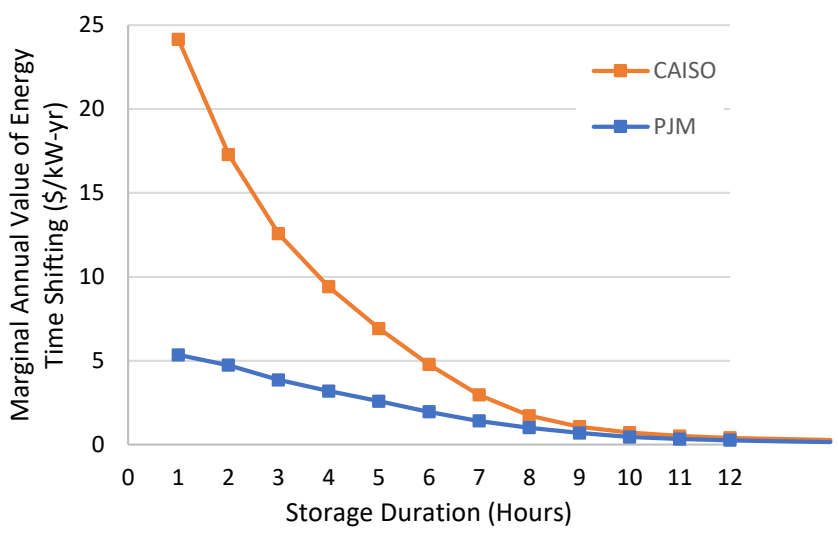

(b) Marginal value

Figure 8. Example of the total and marginal value of energy time-shifting using 2019 energy market values

A combination of the value components from Figure 7 and Figure 8 can be used to estimate a total value, shown in Figure 9a. In this example, most of the revenue is derived from capacity value instead of energy time-shifting, as demonstrated by the gray line, which represents the fraction of total value derived from capacity (assuming a 4-hour duration requirement to obtain a capacity payment of $\$ 90 / \mathrm{kW}-\mathrm{yr})$. In addition, the lower value of energy time-shifting, particularly beyond 4 hours, results in a very small incremental total value once capacity duration requirements have been met. This combination drives the economic performance of storage as a function of duration as illustrated in Figure $9 \mathrm{~b}$, in terms of its $\mathrm{B} / \mathrm{C}$ ratio as a function of storage duration, using the cost curves for a Li-ion battery shown in Figure 3 (page 7).

\footnotetext{
${ }^{24}$ Analysis uses a price-taker model as described in (27) with wholesale market data from CAISO (NOISLMTR_6_N101/SDGE) and PJM (120 LOMB138 KV TR72 12/Commonwealth Edison).
} 


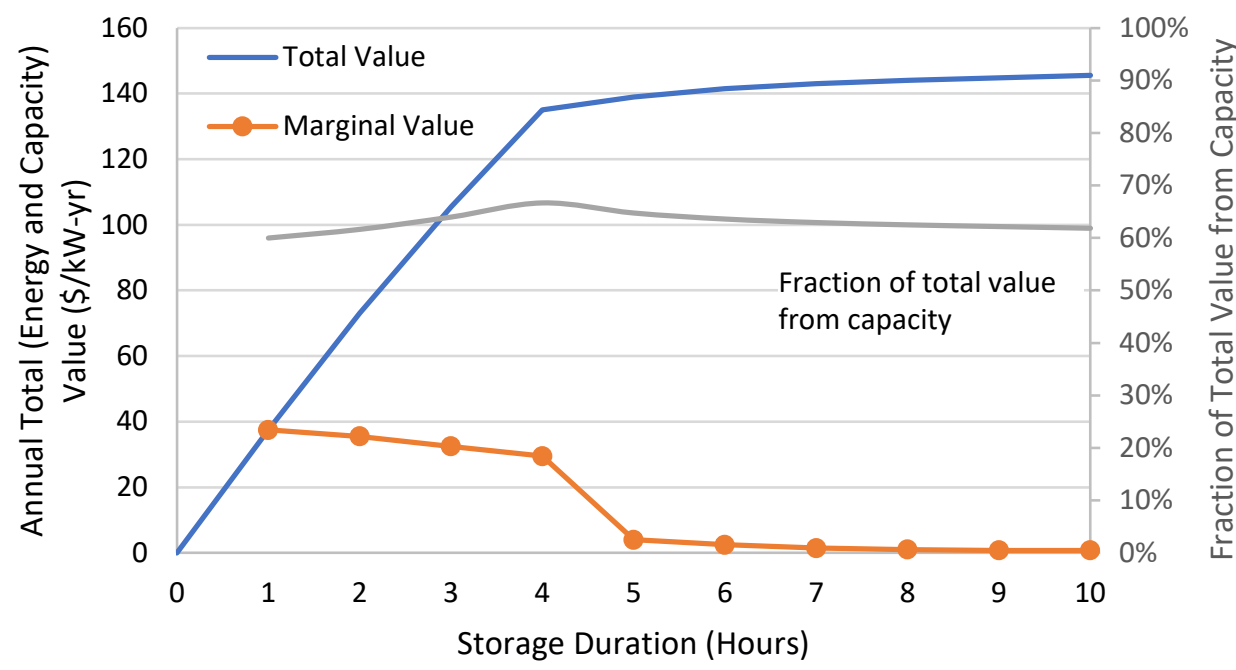

(a) Total value

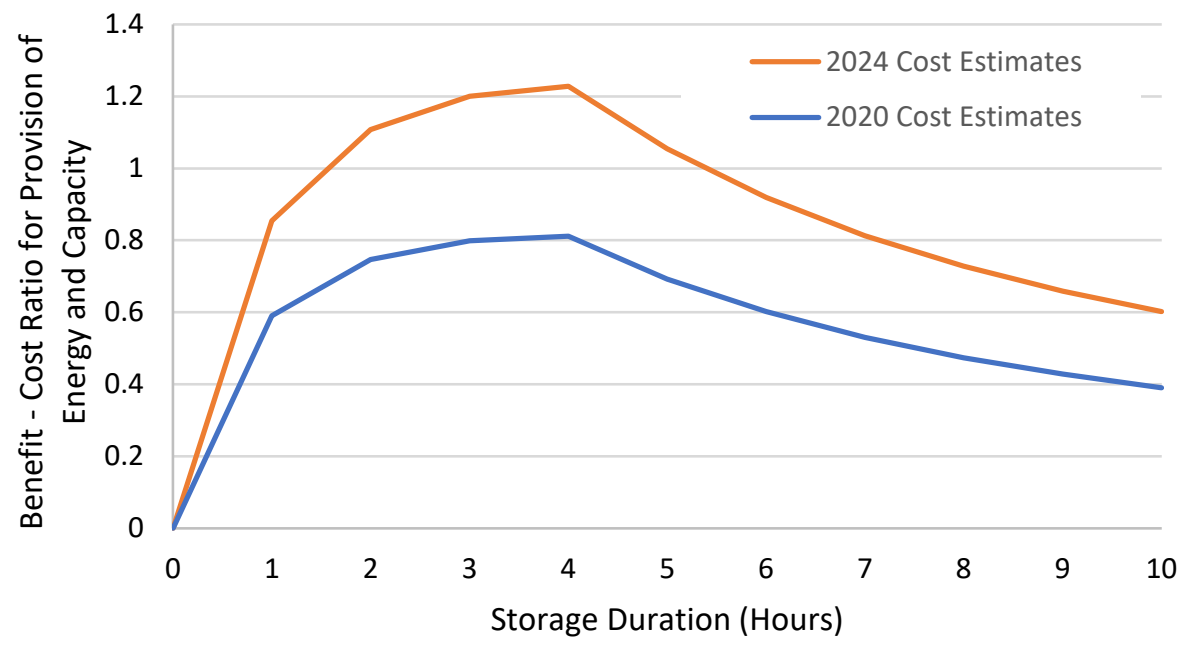

(b) B/C ratio

Figure 9. Example of the total and marginal value and $B / C$ ratio of a battery storage system providing peaking capacity using battery costs from Figure 3 and assuming a 4-hour duration requirement for full capacity value

In this example, the $\mathrm{B} / \mathrm{C}$ ratios increase only up the point of a four-hour duration, at which the marginal benefits drop because the value associated with capacity falls to zero (as shown in Figure 7). Beyond 4 hours, the incremental value of additional duration is only equal to the incremental time-shifting value (Figure 8). As a result, once the minimum duration is met for a device providing a specific market service, there are rapidly diminishing returns for additional duration, suggesting transition points as storage is deployed for various applications. Using the 2020 cost estimates from Figure 3 in this example, the maximum B/C ratio is below one without additional incentives or sources of value. However, using the 2024 estimates, the $\mathrm{B} / \mathrm{C}$ ratio is greater than 1 without any additional incentives. 
This simplified example is generally consistent with the literature, which generally finds a higher value associated with capacity than with energy time-shifting (28). However, this result depends on market structure. In real systems, determination of long-term capacity and energy prices (which are needed for an appropriate comparison of storage to alternatives) is very complicated given the evolving generation mix, actual need for new capacity, and market rules that limit scarcity prices that may occur during periods of peak demand $(10,29)$. In the extreme case of an energy-only market, physical capacity has no inherent value, and capacity-related costs must be recovered entirely through energy prices. Actually estimating the value of time-shifting (and other potential benefits such as congestion management) requires chronological simulations to determine how different resources will operate and these simulations can often reveal additional values compared to conventional resources and these can result in a higher overall value for energy storage (30).

Regardless of approach, there is a clear trend in increasing cost-competitiveness for batteries to provide peaking capacity (even without the extra values associated with operating reserves that are available before the saturation of those markets). ${ }^{25}$ This cost-competitiveness is enhanced by the potential opportunities for deployments in hybrid configurations, where storage can be colocated with generation resources (33). The main advantage of coupling, mostly with PV, is to take advantage of the federal investment tax credit. Additional benefits can be associated with reduced costs, including siting, permitting, and some shared components. These benefits of hybrid systems can be partially offset by decreased operational and siting flexibility, but overall, the attractiveness of storage colocation is reflected in the growing queue for proposed hybrid storage projects, and a large fraction of these proposed projects include a 4-hour duration, which reflects the strong influence of the current market duration requirements, and the declining value beyond 4 hours of duration (34).

\section{Limits to Phase 2: Declining Energy and Capacity Value, and the Impact of Renewable Energy Deployment}

Because of the greater market size for peaking capacity than operating reserves, Phase 2 has much greater potential than Phase 1 . There are about $261 \mathrm{GW}$ of dedicated peaking capacity in the United States, and hundreds of GW of plant retirements are expected in coming decades that include a large amount of peaking capacity (35). Some of these retirements are driven by policy, such as air quality and cooling water regulations, but many retirements are simply due to plant age (36). However, the potential for 6-hour-or-less batteries is only a fraction of this capacity due to the declining value of storage as a function of deployment. As more energy storage is deployed, the peaks become wider and energy storage is less able to meet the resulting longer periods of peak demand. At the same time, additional storage reduces the difference between onpeak and off-peak prices, thus reducing arbitrage/time-shifting benefits.

\footnotetext{
${ }^{25}$ According to several market reports, 4-hour batteries are at or nearing breakeven conditions to be cost-competitive with new gas capacity. However, considerable differences remain among the various reports, and they depend on price forecasts and estimates of market revenue. Many analyses also demonstrate considerable regional variations $(31,32)$.
} 
Figure 10 illustrates this concept in a simulated scenario where California deploys sufficient 4hour storage to meet about $8 \%$ of annual peak demand (35). ${ }^{26}$ In this example, storage has widened the peak period to the point where the net peak is about 6 hours long, meaning a 4-hour device would receive only $4 / 6^{\text {th }}$ of the capacity value of a conventional resource. This deployment would also substantially reduce the time-shifting (energy) value of storage.

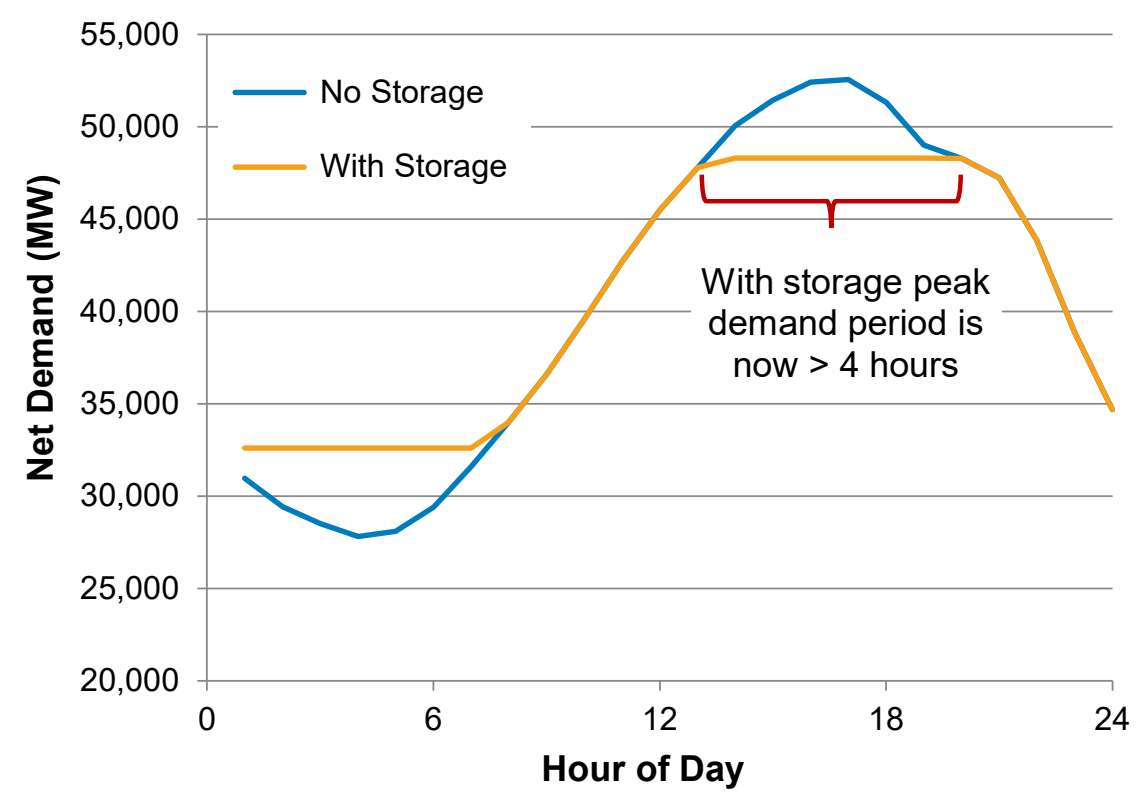

Figure 10. Simulated impact of increased 4-hour storage deployment on net load shape

The limits to Phase 2 are based on this declining energy and capacity value as storage is deployed. However, potentially significant synergies with deployment of solar photovoltaics (PV) could greatly increase Phase 2 storage deployments. PV could increase both the energy and capacity value of energy storage by changing the shape of energy demand, and thus offset the decline resulting from increased storage deployment (35).

Figure 11 illustrates how PV could narrow the net load peak and thus counteract the widening that occurs with increased storage deployment. This example subtracts simulated PV output from normal load in California on the peak day in 2013 (35). This synergy does not require PV or storage to be colocated, as the impact is system wide. However, there are some benefits of colocation, most notably the financial incentive associated with the federal investment tax credit and the reduced costs from shared infrastructure and hardware (33). As a result, much of the deployment of storage in Phase 2 may be associated with PV-plus-battery hybrid projects.

\footnotetext{
${ }^{26}$ We use California as an example based on early deployment of storage, and we use 4-hour storage based on its 4hour duration requirement
} 


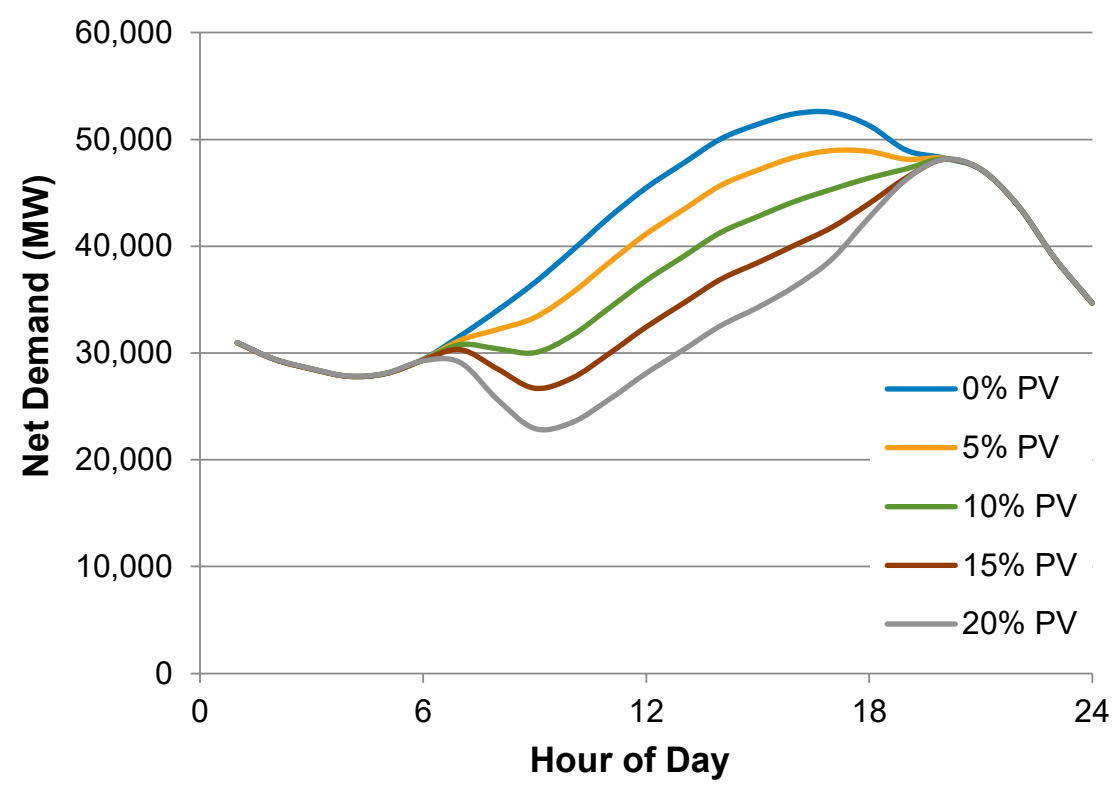

Figure 11. Change in load shape on the day with peak demand in California (2013 simulated data)

Figure 12 illustrates how PV deployment can increase the amount of 4-6 hour storage offsetting capacity requirements and extending Phase 2 considerably. Data from (35) show how much 4-6 hour storage could be deployed with high capacity credit. ${ }^{27}$ At current levels of PV deployment, at the point where about $40 \mathrm{GW}$ of 4-6 hour storage is deployed nationally, the widened peaks would start to greatly decrease the ability of additional storage to reduce the peak. However, Phase 2 opportunities increase to over $100 \mathrm{GW}$ of potential at the point where PV provides about $20 \%$ to $25 \%$ of the nation's electricity.

27 These data represent simulations of 18 regions in the United States adding various combinations of PV and 4-hour and 6-hour storage. It examines the net load in each region and identifies the amount of storage installed at the point at which net load is wider than 6 hours. These numbers are aggregated to create a national number and detailed results by each region is available (35). 


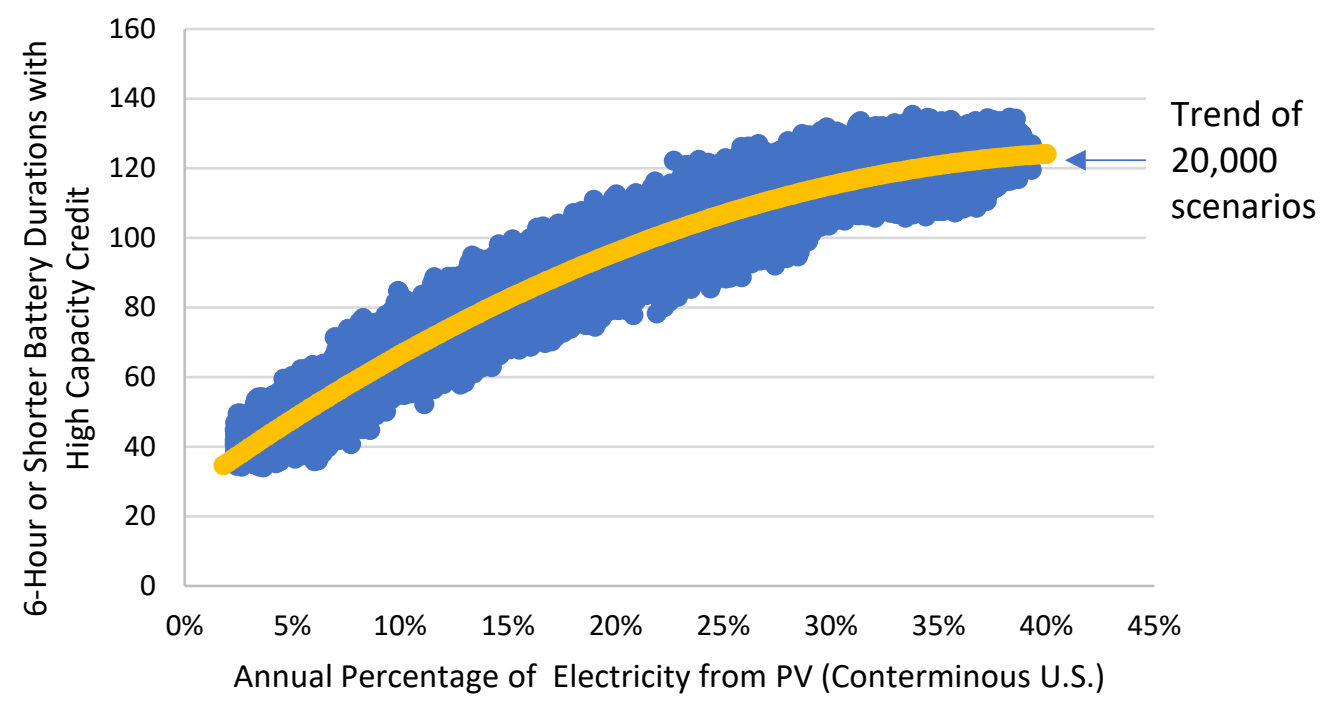

Figure 12. The potential opportunity of Phase 2: National potential of 4-6 hour batteries with high capacity credit 


\section{Phase 3: The Age of Low-Cost Diurnal Storage}

Phase 3 is perhaps the least distinct of our phases. It is characterized by a transition to the deployment of storage technologies that have some combination of lower cost or an ability to provide additional services (resulting in higher value) when compared to current lithium-ion batteries. A key element of this transition is the decline in capacity value of storage with 6 hours or less of capacity (Phase 2). Longer peak periods increase the competitiveness of technologies with lower duration related costs, including new battery chemistries, additional pumped storage, and other technology options discussed later in this section. The deployment that will occur in Phase 3 is more uncertain than that of earlier phases, as it depends on the degree to which storage costs decline and VRE deployments increase.

\section{Phase 3 Opportunities: Capacity, Energy, and Transmission Services}

While there will likely be considerable overlap between Phase 2 and Phase 3, the key distinction in the transition to Phase 3 is the wider net peak demand periods, which require lower durationrelated costs for storage to provide cost-competitive capacity services. Indicative of this transition between Phases 2 and 3, Figure 13 illustrates two days of high load (August 29-30) in California in a modeled scenario with a $30 \%$ annual contribution from PV. ${ }^{28}$ It shows the substantial narrowing of the net peak from solar, and then the widening of the peak after addition of 4- and 6-hour storage in Phase 2, shown as the green line. The assumed 9,000 MW of battery peaking capacity has been deployed in Phase 2 with nearly full capacity credit, meaning the net load peak has been reduced by about $9,000 \mathrm{MW}$. This mix of storage has an average duration of about 4.3 hours. The net load peak is now about 7 hours long. Therefore, any additional storage with less than 7 hours of duration will need to be derated, thus reducing its value and thereby requiring reduced costs to be cost-competitive.

The red line in Figure 13 shows the impact of Phase 3 deployment of another 7,000 MW of storage capacity with an average of 8 hours of duration. This deployment further reduces net load, and so provides additional firm capacity. While multiple storage power and capacity configurations could achieve this result, continued deployment of storage in Phase 3 requires significantly more energy capacity per unit of avoided conventional capacity.

Longer-duration peaks decrease the value of shorter-duration storage (i.e., produce a decline in the marginal value of incremental duration). The change in value proposition for longer net peak periods is illustrated in Figure 14, which shows how the marginal value of capacity falls as the length of the peak period moves from 4 to 10 hours. Assuming an annualized value of $\$ 90 / \mathrm{kW}$ for firm capacity, the marginal value of each of the first 4 hours with a 6-hour duration requirement is $\$ 22.5 / \mathrm{kW}-$ yr per hour $(\$ 90 / 4)$. But as the requirement to achieve full capacity credit increases, this marginal value falls to $\$ 90$ divided by the duration requirement (up to the duration requirement), dropping to $\$ 9 / \mathrm{kW}$-yr per hour when the net load peak is 10 hours long.

\footnotetext{
${ }^{28}$ Figure 2 and Figure 3 were generated using 2013 load and simulated wind and solar data and storage dispatched in the REFlex model (37).
} 


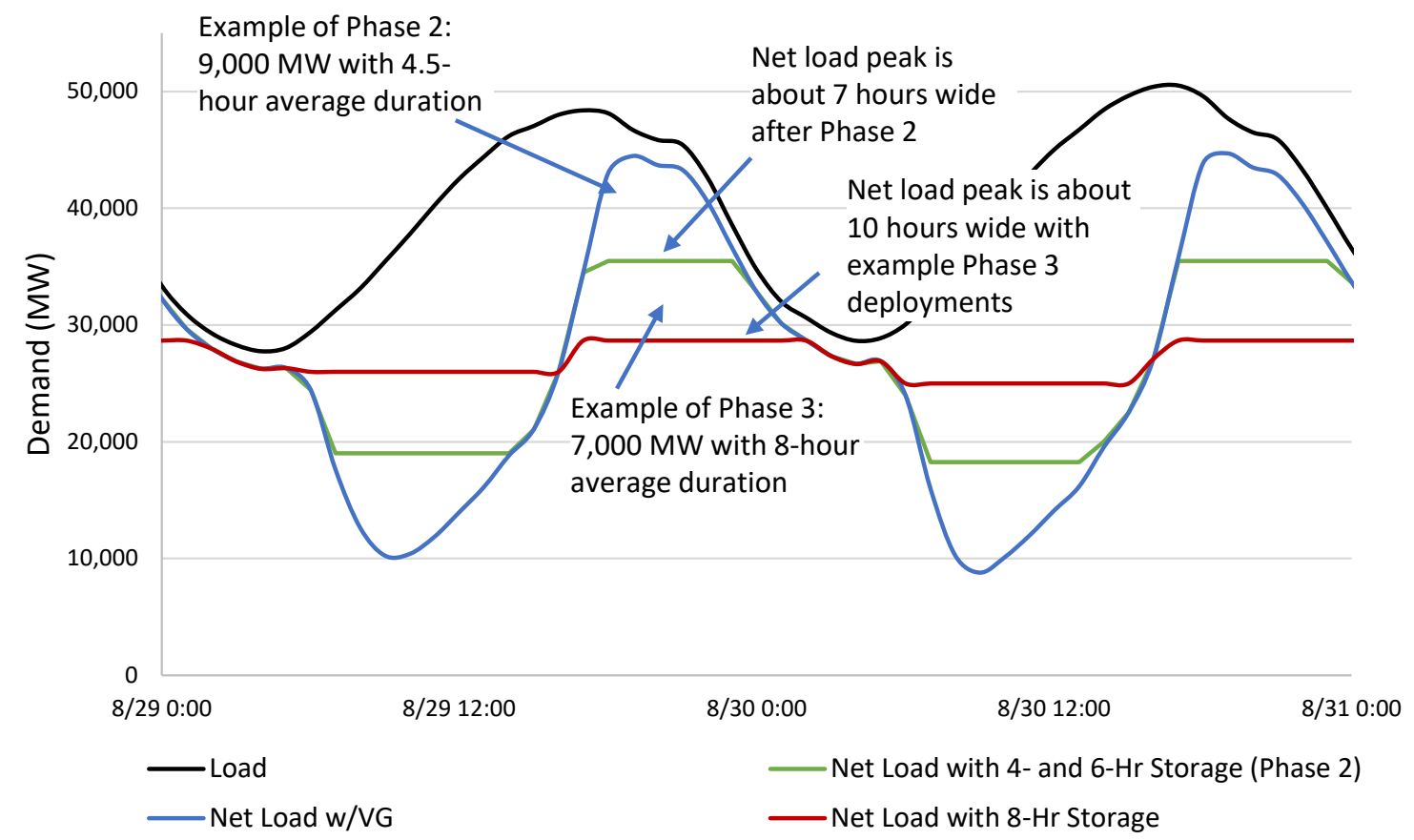

Figure 13. Example of longer-duration storage providing system capacity in California during the summer peak

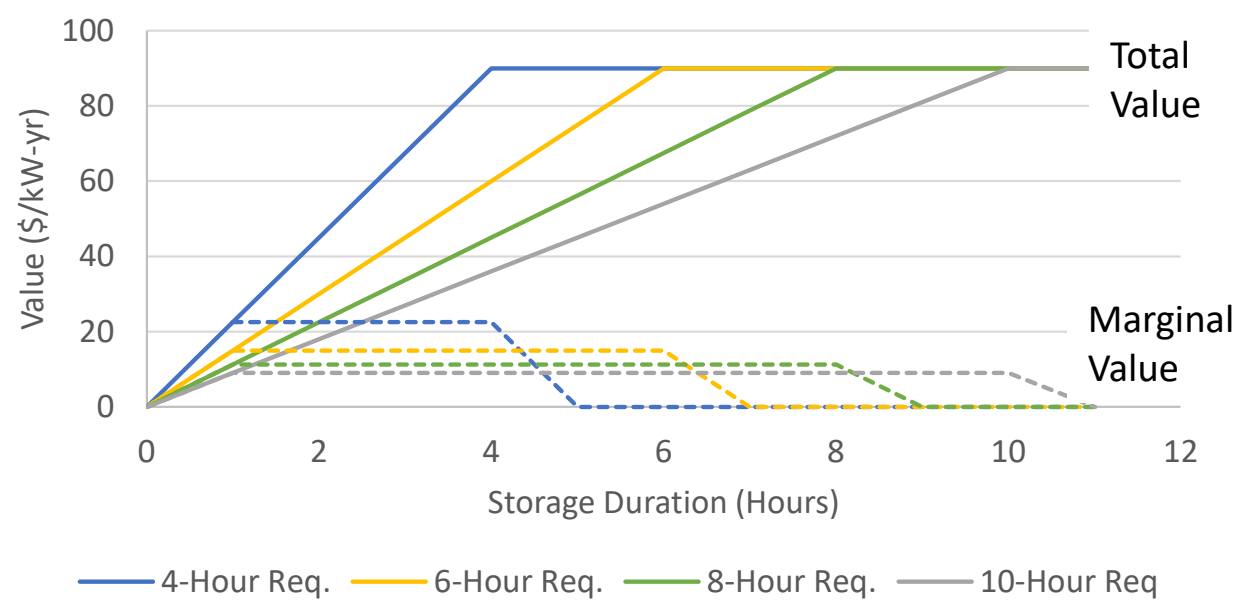

Figure 14. Annualized capacity value as a function of duration for different capacity credit duration requirements

The longer net peak periods in Phase 3 do not inherently require longer-duration storage. Storage plants with 6-hour or shorter duration can still provide capacity, just with a reduced capacity credit that requires a reduction in cost to offset the lower value. Alternatively, reduction in the energy component (duration) costs could allow for deployment longer-duration diurnal storage (8-12 hours) to continue to provide full capacity while further increasing the energy timeshifting value. 
The actual choice between these two options - shorter-duration storage with lower capacity credit or longer-duration storage with full capacity credit-will be driven by many factors, including the value of other services, such as time-shifting. For example, to reduce the net load by $100 \mathrm{MW}$ at the point where the peak net load is 8 hours, we would need $800 \mathrm{MWh}$ of stored energy. We could achieve this by adding a 100-MW device with 8-hours of capacity. Alternatively, we could add a 133-MW device with 6-hours of capacity (meaning the plant would operate at less than full power output when discharging to reduce the peak by $100 \mathrm{MW}$ ). Both options provide the same amount of stored energy. For assuming the same storage technology, the 133-MW storage plant would almost certainly cost more than the 100-MW storage plant, as they have the same energy capacity. This additional $33 \mathrm{MW}$ of power-related costs provides no additional capacity-related value. But the additional power capacity might provide additional energy shifting opportunities and thus depending on the value of energy shifting or other value streams, different configurations may be cost-effective.

Figure 15 (page 29) illustrates this concept. It shows how storage with a higher power-to-energy ratio (shorter-duration) storage allows for greater capture of curtailed energy. This could result in potentially higher energy shifting value, particularly under scenarios of greater PV deployment, and potentially offset the decline in capacity value. Figure 15a shows the load and VRE supply in the same California scenario as shown in Figure 13, but on two spring days. The large amount of solar energy, combined with system flexibility limits, results in a surplus of solar energy. Figure 15b show how storage deployed for peaking capacity (Phase 2) can absorb much, but not all of this curtailed solar, leaving additional opportunities. If we add the $800 \mathrm{MWh}$ of storage needed to reduce peak demand, we can consider the impact of power capacity and duration on energy shifting value. The residual curtailment on each day lasts for 6 hours, so if we add the lower-cost option (100 MW of 8-hour storage), it can charge at $100 \mathrm{MW}$ for 6 hours and absorb only $600 \mathrm{MWh}$ of curtailment, meaning $200 \mathrm{MWh}$ of storage capacity is unused. Alternatively, the $133 \mathrm{MW}$ of 6-hour storage can charge at full power capacity and can store the full $800 \mathrm{MWh}$. As a result, the higher power capacity is better aligned with the higher power associated with PV overgeneration events.

This result shows the trade-off between power and energy for the two applications. For provision of peaking capacity, the long peaks result in energy limits that are better suited for longer durations of storage. But for time-shifting, particularly in high PV scenarios, storage may be power limited. With sufficiently high value of time-shifting, this could justify the additional power-related costs associated with the shorter-duration storage.

As a result, it is possible that shorter-duration storage may still be deployed in Phase 3 to capture the high-power curtailment events in the high-solar scenario. Alternatively, longer-duration storage is potentially more suited to capturing curtailed energy in high-wind scenarios that do not feature high-power, short-duration curtailment events (37). Longer-duration storage can provide additional value beyond system capacity and energy time-shifting. An example is transmission deferral and congestion management. This application uses storage as a partial alternative to transmission upgrades. This service can be provided by shorter-duration storage, such as the battery peaking plants deployed in Phase 2, but longer-duration storage provides even greater flexibility to avoid upgrades. Storage can also improve utilization of transmission for remote VRE resources (38). Some of the highest-quality wind resources in the United States are in more-remote locations that might require dedicated new long-distance lines to high-population 
load centers. Utilization of these transmission lines will be limited by the capacity factor of the wind resource (increasing costs per unit of delivered energy). Because wind generation is often anticorrelated with load on a diurnal basis, storage can be used to increase transmission utilization (increasing the amount of energy that can be delivered per unit of transmission capacity), and it can provide system capacity and time-shifting. ${ }^{29}$

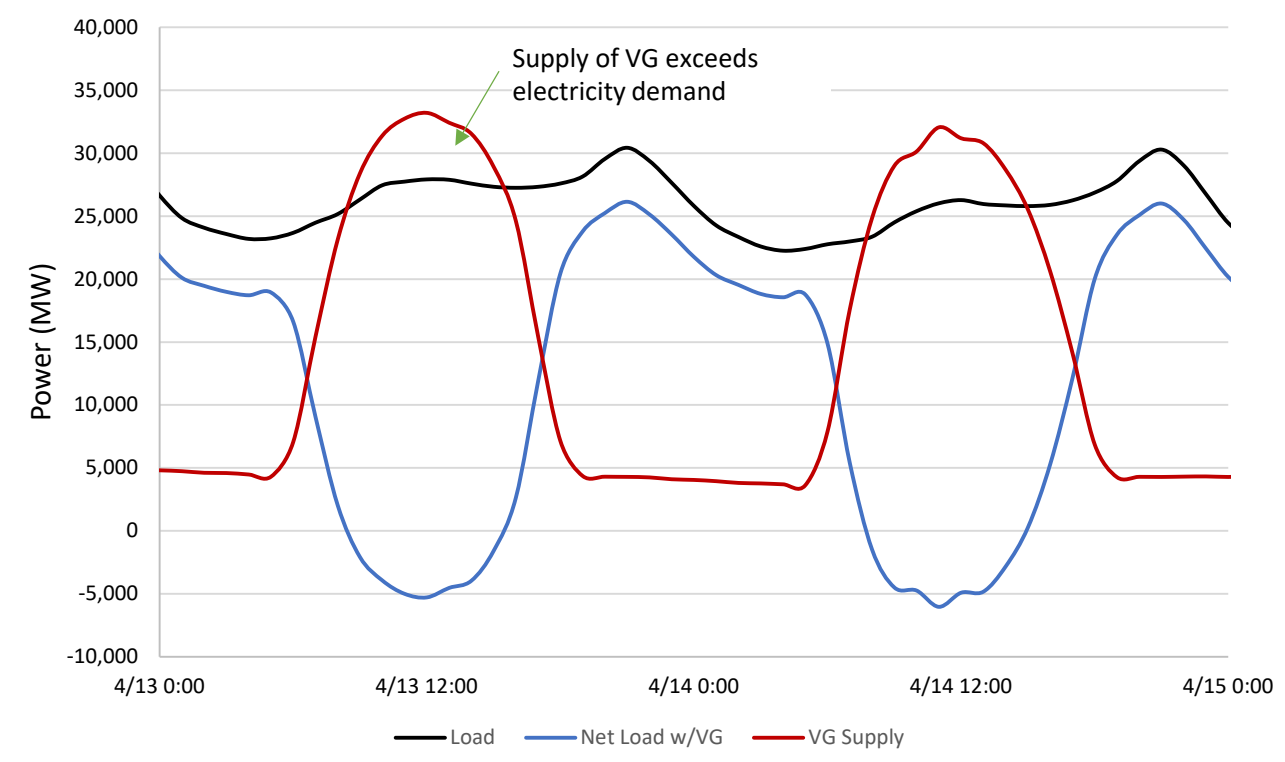

a) VRE supply and net load during two spring days

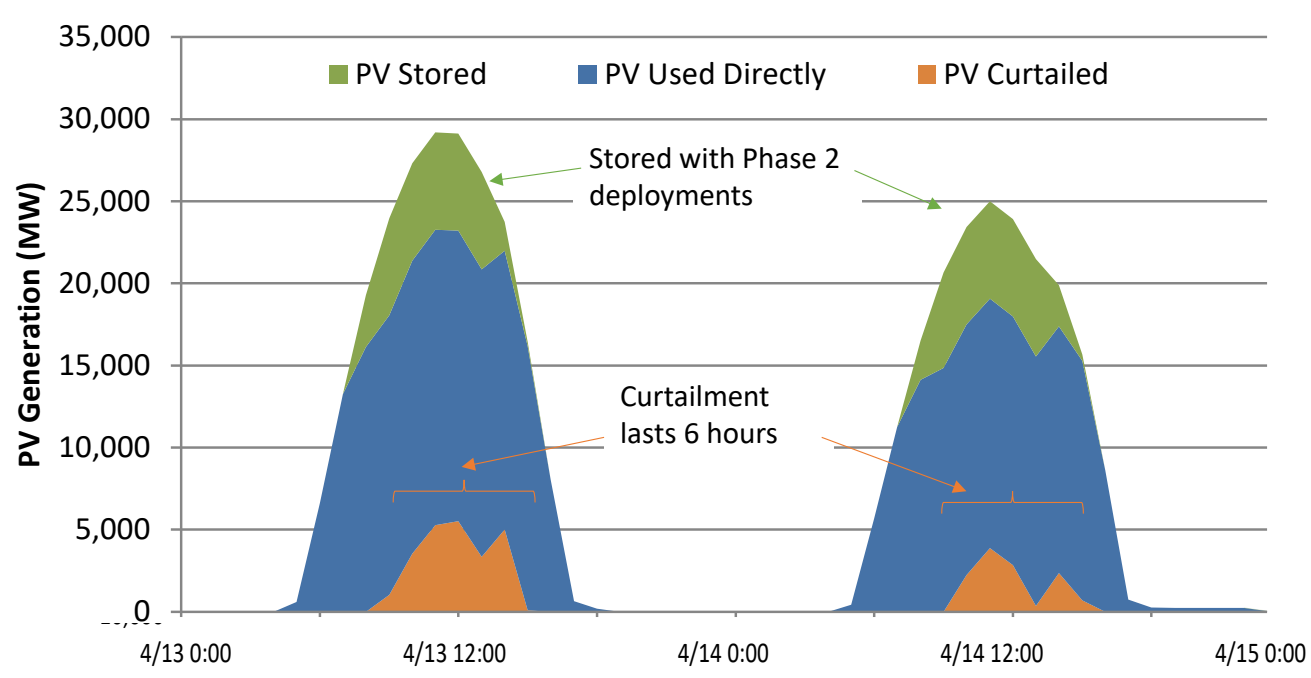

b) Residual curtailment after Phase 2 storage deployments

\section{Figure 15. Availability of curtailed energy during a spring period showing length of curtailment events}

\footnotetext{
${ }^{29}$ Transmission deferral is an example of an application that can be partially additive ("stacked") with other services, but careful analysis is required because this application inherently limits the flexibility of the storage device to charge and discharge independently of transmission constraints.
} 
Because of the uncertainties about energy storage value in the evolving power grid, determining the cost requirements needed to reach cost-competitive storage in Phase 3 is difficult. However, several technologies have the potential to achieve the costs reductions required for competitive deployment in Phase 3. These include batteries with lower-cost electrolyte materials, and a variety of thermal storage technologies and mechanical-based storage technologies, compressedair energy storage, liquid air energy storage, and novel gravity-based technologies $(7,28)$. Nextgeneration pumped storage could also be cost-competitive as new technologies could reduce costs and improve performance (4). This technology includes deployment of closed-loop pumped storage plants that reduce siting constraints and permitting times, while new pump/turbine systems can provide higher efficiency and faster response (6). In addition to new pumped storage capacity, upgrades at existing sites could add more power capacity, improved efficiency (resulting in additional storage capacity), and more flexible operation.

\section{Limits to Phase 3: Flattened Loads and the Impact of Seasonal Mismatch}

The opportunities for diurnal storage technologies of 12 hours or less (i.e., in both Phase 2 and Phase 3 ) is very large, with upper bounds depending on a number of factors. Specific technologies might have technical or physical limits, such as geological conditions needed for both PSH and compressed-air energy storage. However, the ultimate limits to Phase 3 are economic in nature and are driven by both the cost reductions of storage and the declining value of storage. The declining value is a function of deployment, which is similar to that occurring in Phase 2, and it results from very long net-load peaks that can occur with significant storage deployment.

Figure 16 illustrates a challenge of continued storage deployment, even assuming much longer storage durations. It simulates a future in the ERCOT grid assuming $80 \%$ of its annual energy is derived from RE (36\% PV, 42\% wind, and 2\% nonvariable RE). Storage is deployed with an installed total capacity equal to about $45 \%$ of the annual peak and across a mix of durations from 4 to 12 hours, and a system-wide average of about 10 hours. ${ }^{30}$ The system has thermal capacity with a capacity equal to about $33 \%$ of the annual peak, which provides the remaining $20 \%$ of annual demand, including both periods of peak demand, or low RE output. Figure 16a shows the limits to storage providing capacity value as it illustrates a two-day period in the late summer with the annual peak demand. The combination of peak load reduction and storage charging produces a nearly flat net load for more than 80 hours. This means that additional storage will be unable to reduce the net load, substantially reducing its value to the system.

\footnotetext{
${ }^{30}$ This simulation uses 2013 load data with an annual peak of $67 \mathrm{GW}$.
} 


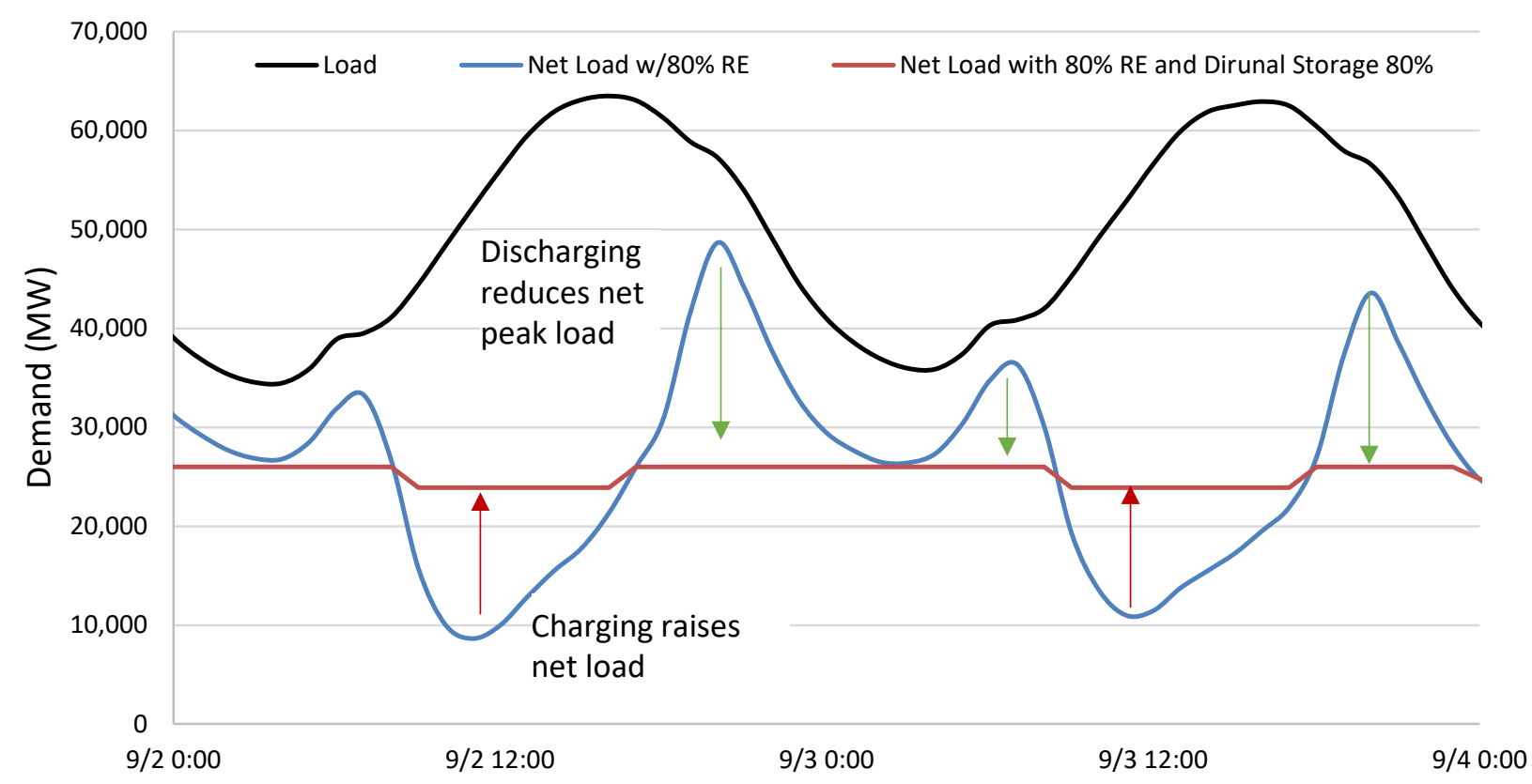

a) Decline in capacity value due to a flattened net load

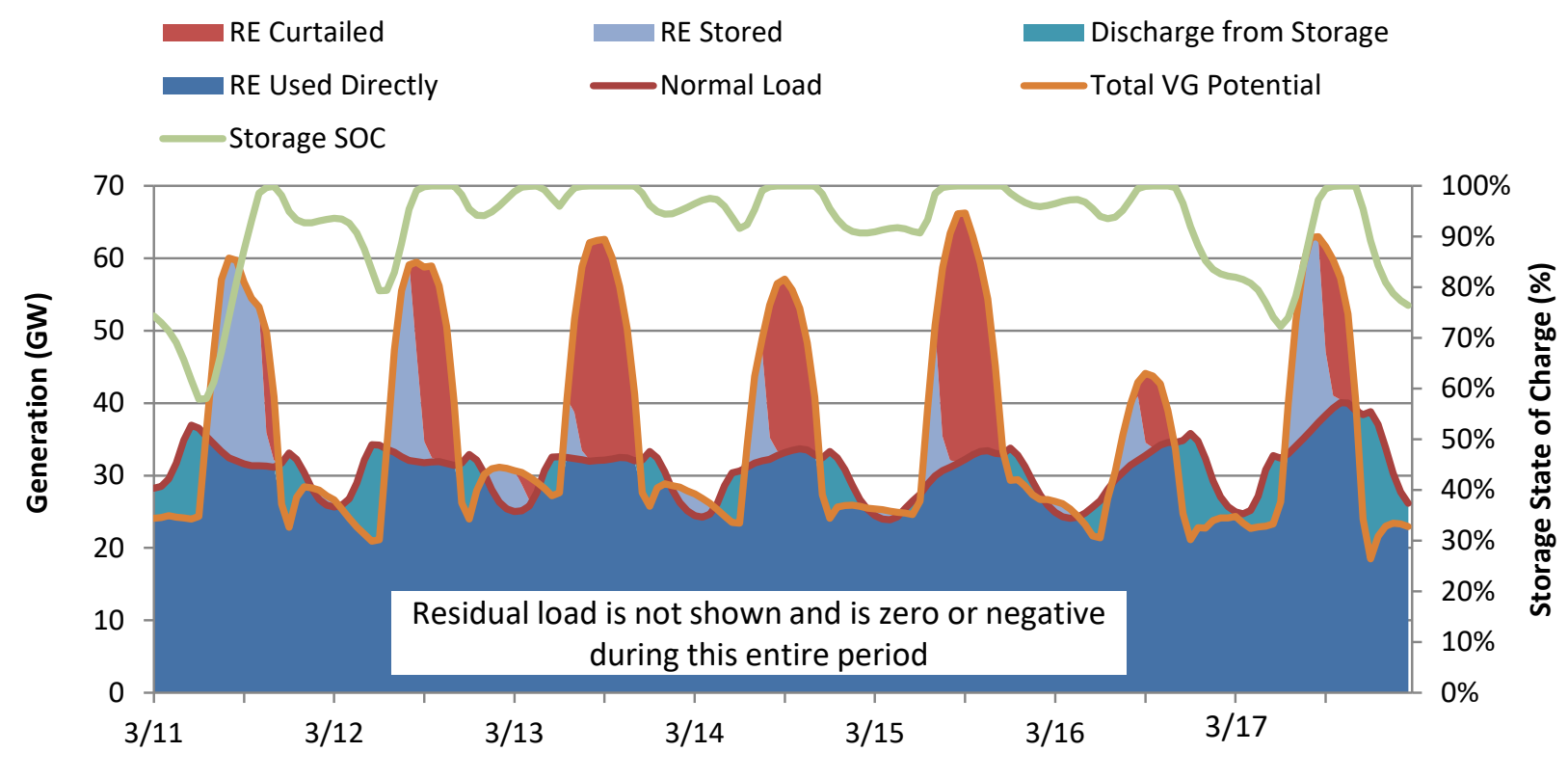

b) Decline in time-shifting value due to zero net load.

Figure 16. Simulated flattened loads in ERCOT at $80 \%$ RE

Figure $16 \mathrm{~b}$ shows how the energy time-shifting value is limited at these levels of storage deployment. It shows the same scenario, but during a spring week with lower demand and higher VRE output than in the summer period in Figure 16a. During this spring week we have met 100\% of the demand with RE, and much of the RE generation is curtailed, as the storage is completely full during periods of overgeneration. In fact, at $80 \% \mathrm{RE}$, there is no net load during the 31-day period from March 3 to April 4. This means any additional storage will have no time-shifting value during the entire period. 
The interdependence of storage and VRE deployment creates a deployment opportunity curve for Phase 3 services that is similar in nature to that for capacity in Phase 2 (Figure 12). An example for capacity is provided in Figure 17, which shows an estimate national potential for longerduration storage deployment with high levels of capacity credit (meaning the net load peak is less than 12 hours long) as a function of overall RE deployment. ${ }^{31}$

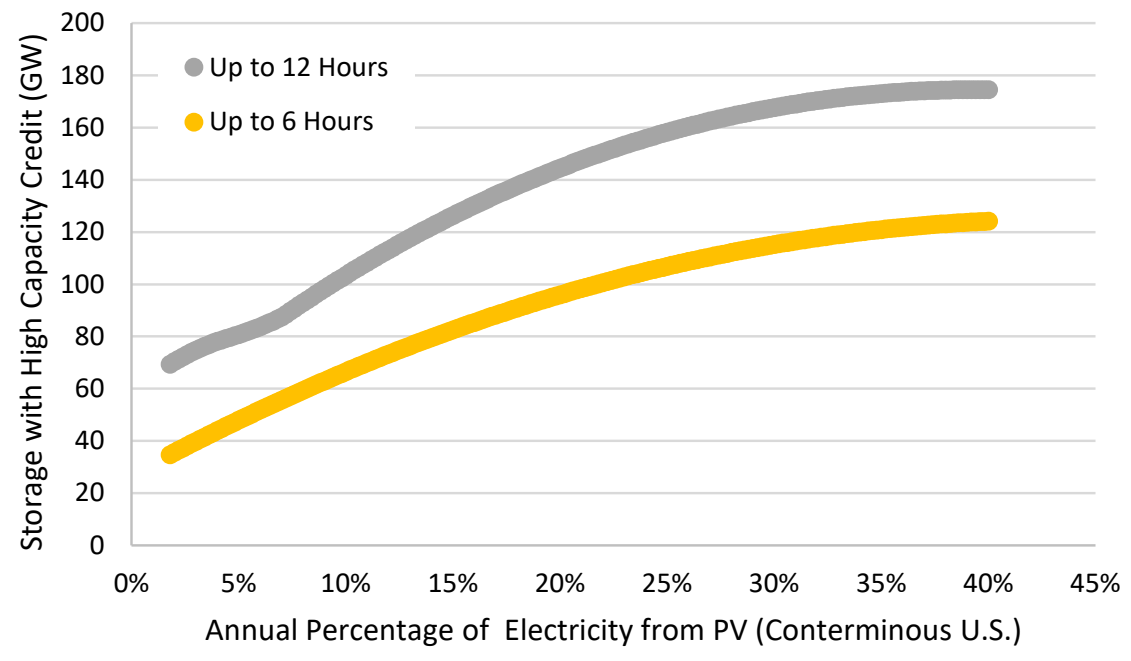

Figure 17. National opportunities for long-duration (up to 12-hour) storage providing capacity services in Phase 3

Overall, at higher levels of VRE deployment, cost-effective storage with up to 12 hours of duration creates more than $50 \mathrm{GW}$ of potential for capacity-related services, but Figure 17 does not include the considerable addition $(50+\mathrm{GW})$ of opportunities for energy time-shifting and potentially transmission applications (23).

It should be noted that scenarios that explore the limits of Phase 3 often consider VRE contributions that exceed $50 \%$ on an annual basis. At these levels, the seasonal mismatch of RE supply and normal demand may require even longer-duration or seasonal storage technologies to continue further RE deployment. Such a transition represents a final phase in both storage deployment and power system decarbonization.

\footnotetext{
${ }^{31}$ Figure 17 was generated using the same model and data used to generate Figure 12 (35), but extended the analysis to 12 hours. These numbers are cumulative, and represent the addition of multiple durations, so the average duration across the entire deployment is considerably less. Wind does not show a significant diurnal trend that changes the ability of storage to provide firm capacity (35).
} 


\section{Phase 4: The End Game-Multiday to Seasonal Storage}

Given the long time horizon associated with Phases 2 and 3, the transition to Phase 4 is highly conjectural. Studies to date have not identified a hard technical or economic limit to RE deployment with only diurnal storage, but have also found that approaching $100 \% \mathrm{RE}$, the seasonal mismatch of supply and demand leads to significant challenges $(39,40)$. This creates a potential opportunity for storage with more than 12 hours of duration, possibly extending to seasonal storage.

Alternatively, some transitions to longer-duration storage technologies might not inherently be tied to very high RE scenarios. Our four phases framework assumes most storage technologies deployed in the coming decades will continue to have a significant cost associated with duration. This cost drives the transition from shorter to longer durations, with longer durations only being deployed when the opportunities for shorter duration are largely saturated. However, many of the very long-duration storage technologies under development have very low duration-related costs. Technology breakthroughs, or dramatic cost reductions associated with deployment at scale could introduce storage with close to zero costs associated with duration and could thus result in much earlier deployment and overlap with previous phases.

Barring dramatic, near-term cost reductions, however, we expect the primary driver of very longduration storage to be the seasonal mismatch of VRE resource supply and normal demand.

\section{Characterizing Seasonal Storage}

The decreasing utilization of both VRE and diurnal storage - and the associated increasing costs - drives the motivation for seasonal storage or other resources to further decarbonize the electric sector. The basic concept of seasonal storage is to shift the otherwise curtailed RE available in the spring to periods of higher demand or lower RE availability. Figure 18 illustrates a scenario of a 98\% RE system in ERCOT, demonstrating the role of seasonal storage to shift springtime RE generation to the summer. ${ }^{32}$

\footnotetext{
32 The simulation uses the same data and tools as used for Figures 2 and 3, but assumes 47\% from wind, 47\% from $\mathrm{PV}, 3 \%$ from hydro and other dispatchable renewables and 3\% from thermal capacity.
} 


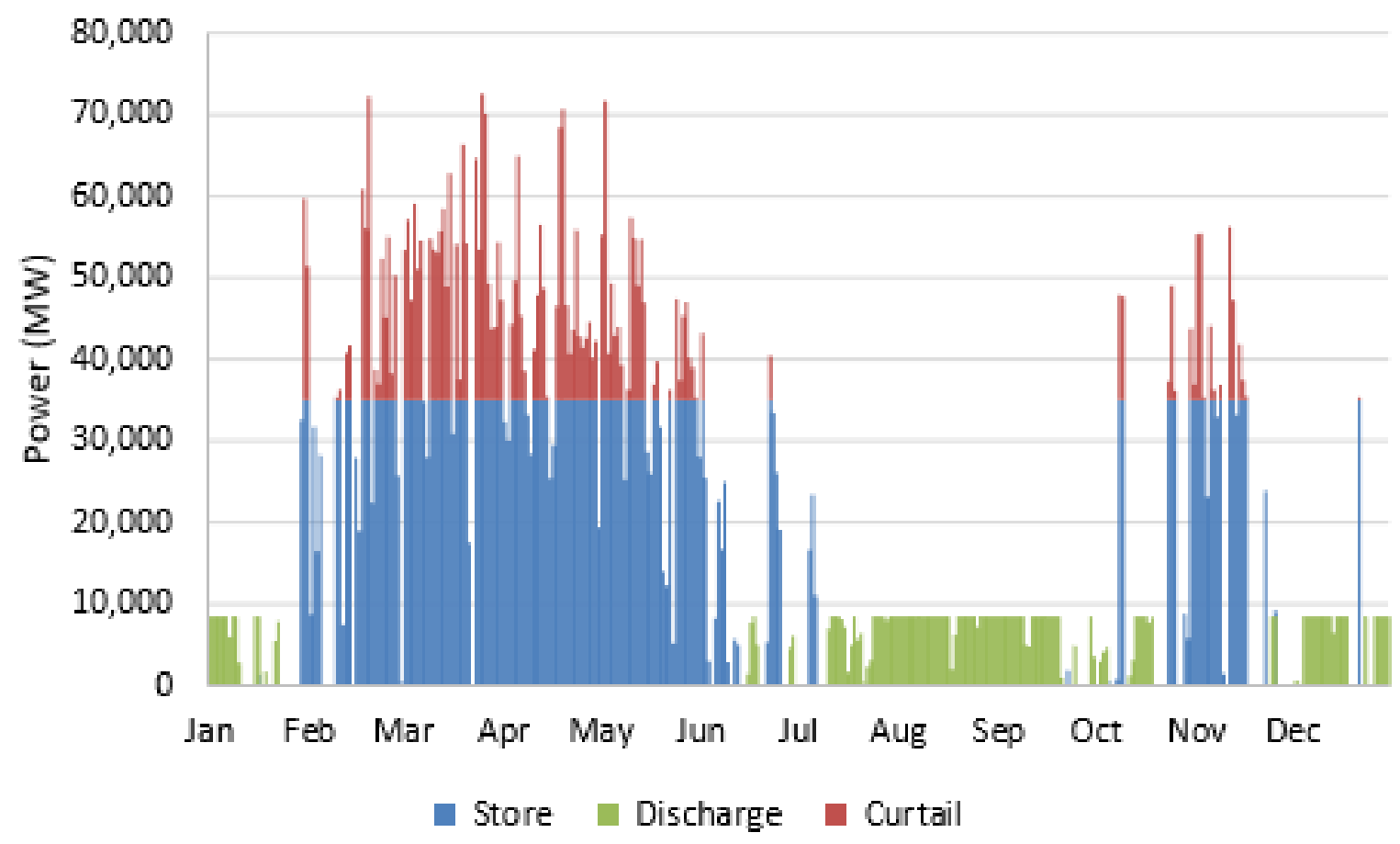

Figure 18. Chronological results of seasonal storage in a $98 \%$ RE scenario

A major outstanding question of scenarios such as that shown in Figure 18 is when or whether seasonal storage will become cost-competitive with other approaches, including low-carbon, non-RE generation.

Several storage technologies potentially offer multiday to seasonal duration, and they often use geologic storage given the large volumes required. These technologies include compressed-air and hydroelectric storage, which are typically considered diurnal technologies but have the potential for much longer durations depending on local geological conditions. Many concepts for seasonal (or beyond) storage involve the production of a liquid or gas fuel, which is typically envisioned to start with the production of hydrogen via electrolysis of water. This hydrogen then is either stored directly or undergoes additional processes to convert it to a more easily storable and transportable liquid or gas fuel. This option includes the possible production of hydrocarbon fuels using carbon dioxide produced either from fossil fuel combustion or via direct air capture. Underground storage of hydrogen, methane, or other fuels allows for storage capacity measured in months or years, and largely decouples the power- and energy-related components.

These processes are often considered to be part of a larger economy-wide transition in which storable low-carbon fuels are used for transportation and industry. This could include transportation subsectors that are difficult to electrify, such as long-haul freight, aviation, and shipping, and industrial processes including metals and cement production and bulk chemicals (41). In the electric sector, the process allows for the use of off-season renewable production (largely in the spring) to generate the storable fuel, which can be used at a later time of high demand or low renewable production.

The timing of a transition from Phase 3 to Phase 4 depends on multiple factors. The power system is not anticipated to have a significant need for seasonal storage until deployment of VRE 
resources greatly increase, particularly as there are plenty of opportunities for diurnal shifting using Phase 2 and Phase 3 technologies. Phase 4 could occur much earlier if there were some combination of limited advancement of Phase 3 technologies and improvements in Phase 4 technologies. For example, breakthroughs in fuel cell technologies could create accelerated demand for hydrogen in transport or electricity peaking applications even before large amounts of surplus renewable generation become available.

Alternatively, it is possible that Phase 4 energy storage technologies are deployed in a more limited fashion, or even never deployed at scale in the electric sector. Continued cost declines in VRE along with diurnal storage could allow for continued economic deployment with higher levels of curtailment. This VRE overbuild concept allows for even greater decarbonization levels without the need for seasonal storage, particularly if the storage technologies are accompanied by alternative low-carbon technologies - including fossil carbon capture and storage (CCS), direct air capture/CCS, biofuels (potentially with CCS), nuclear, or advanced demand response - that better align RE supply with demand (42-44).

Furthermore, analysis of seasonal storage technologies is complicated because they are, by their nature, very different from diurnal storage technologies. Underground storage can produce extremely low energy component costs, and as a result, the ability to store weeks or months of energy can produce artificially low overall costs when measured only by duration. A direct comparison is also complicated because many seasonal storage technologies (particularly those that involve fuel production) have much lower round-trip efficiencies than many diurnal storage technologies. However, the biggest challenge in comparing of many seasonal storage technologies and alternatives lies in the potential shared use of infrastructure to produce fuels for a variety of end uses beyond electricity. It is possible to envision costs of low-carbon fuel production infrastructure being largely paid for by other industries, with electricity use being a minor contributor and even being able to leverage existing assets such as legacy combustion turbines, which could accelerate deployment of Phase 4 technologies.

\section{Opportunities for Seasonal Storage}

Ultimately, answers to questions about both the transition to Phase 4 and the potential size of Phase 4 lie in the relative competitiveness and the declining costs for the suite of low-carbon technologies that could address the seasonal mismatch problem.

Despite these uncertainties, the potential opportunities for cost-competitive seasonal storage is large. Under scenarios where even $90 \%$ of electricity demand is met by RE plus diurnal shifting technologies, a large amount of physical generation capacity is still needed to meet the remaining $10 \%$, as illustrated in Figure 19. Figure 19a show a load duration curve for a $90 \%$ RE scenario in ERCOT, while Figure $19 \mathrm{~b}$ illustrates a $90 \%$ RE scenario in California. ${ }^{33}$ In the ERCOT case, capacity providing the last $10 \%$ of the annual demand requires about $35 \%$ of the capacity, meaning that even at $90 \% \mathrm{RE}$, nearly $20 \mathrm{GW}$ of additional capacity is needed to meet peak demand. In California, a proportionally smaller amount of additional capacity $(9 \mathrm{GW}$, or $18 \%$ of the total) is needed at $90 \% \mathrm{RE}$, largely because of the significant contribution of RE resources

\footnotetext{
33 The assumed contribution from RE in ERCOT is 41\% PV, 46\% wind, and 3\% nonvariable RE. For California, the mix is $50 \% \mathrm{PV}, 21 \%$ wind, and $19 \%$ nonvariable $\mathrm{RE}$
} 
with high capacity credit, including hydro and geothermal, along with the greater contribution of longer-duration pumped storage.

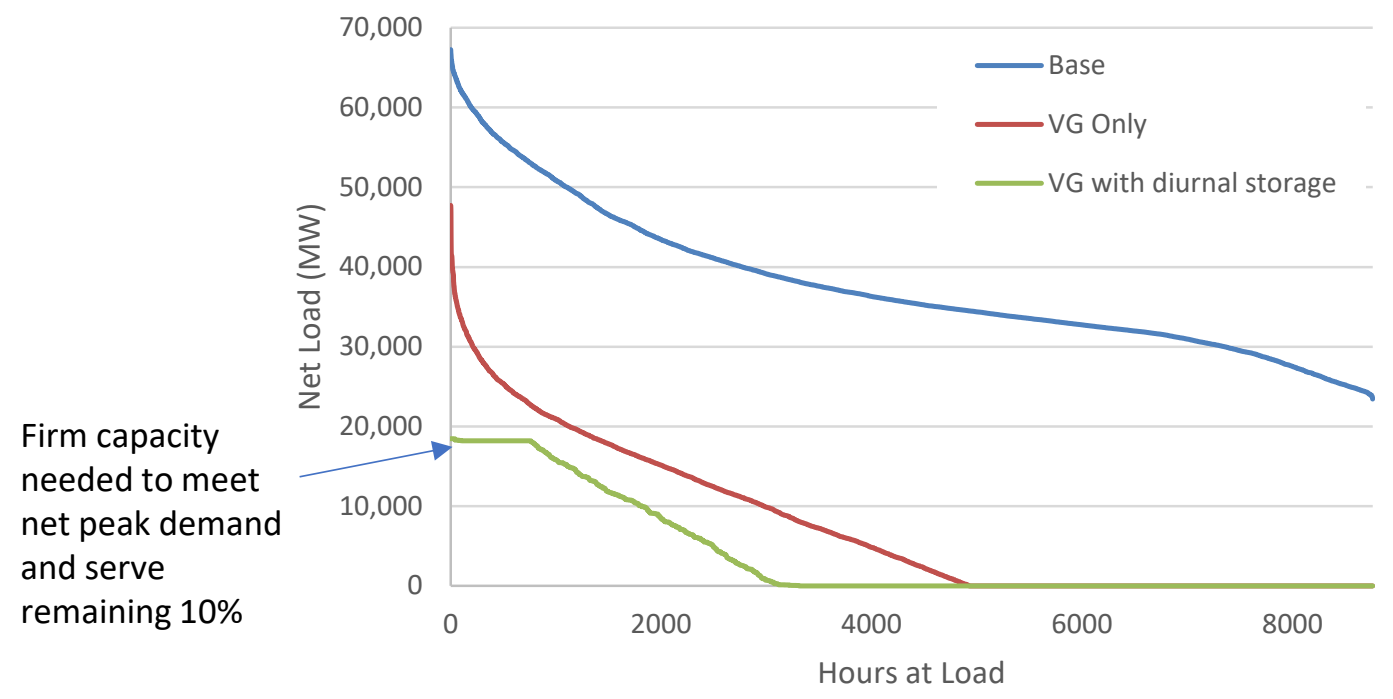

(a) ERCOT

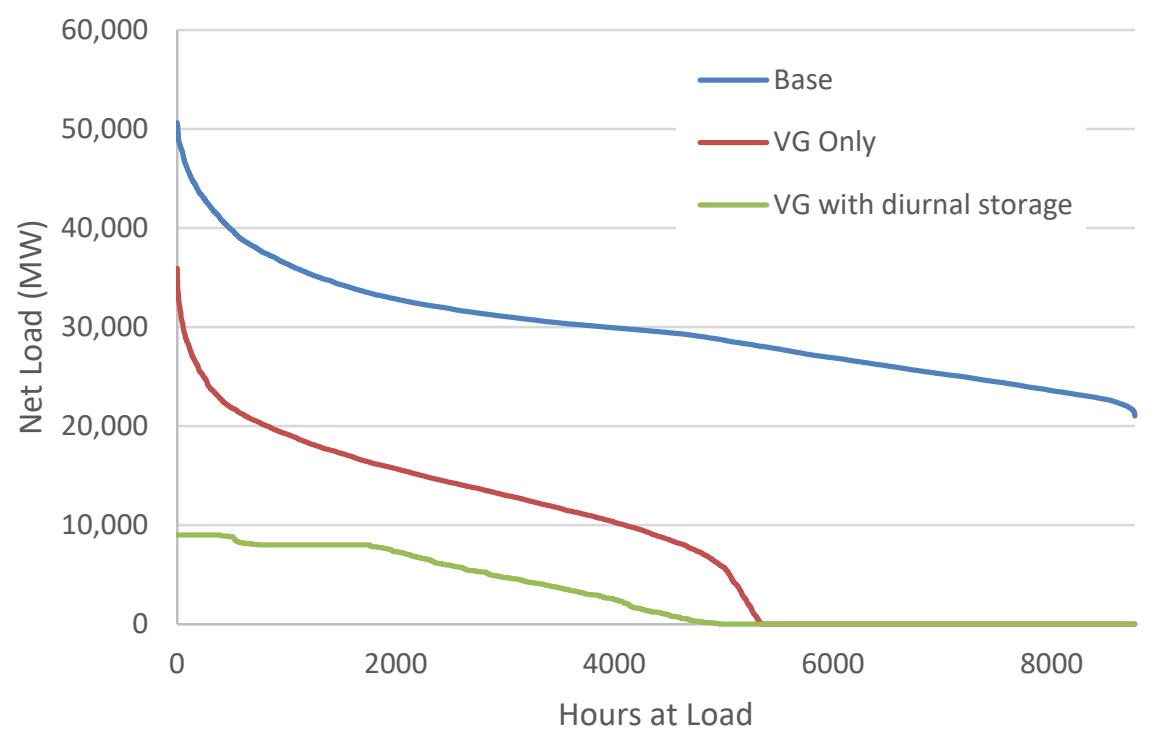

(b) California

Figure 19. Residual load duration curves at $90 \%$ RE showing the need for significant firm capacity 
We applied this approach to the entire United States in a set of scenarios where $80 \%-90 \%$ of the electricity demand in the conterminous United States is provided by various combinations of RE resources and diurnal storage. ${ }^{34}$ We measured the residual peak demand in each region and aggregated the results. The results shown in Figure 20 provide the residual capacity requirements that would need to be met by some combination of resources with high capacity credit that could include seasonal storage.

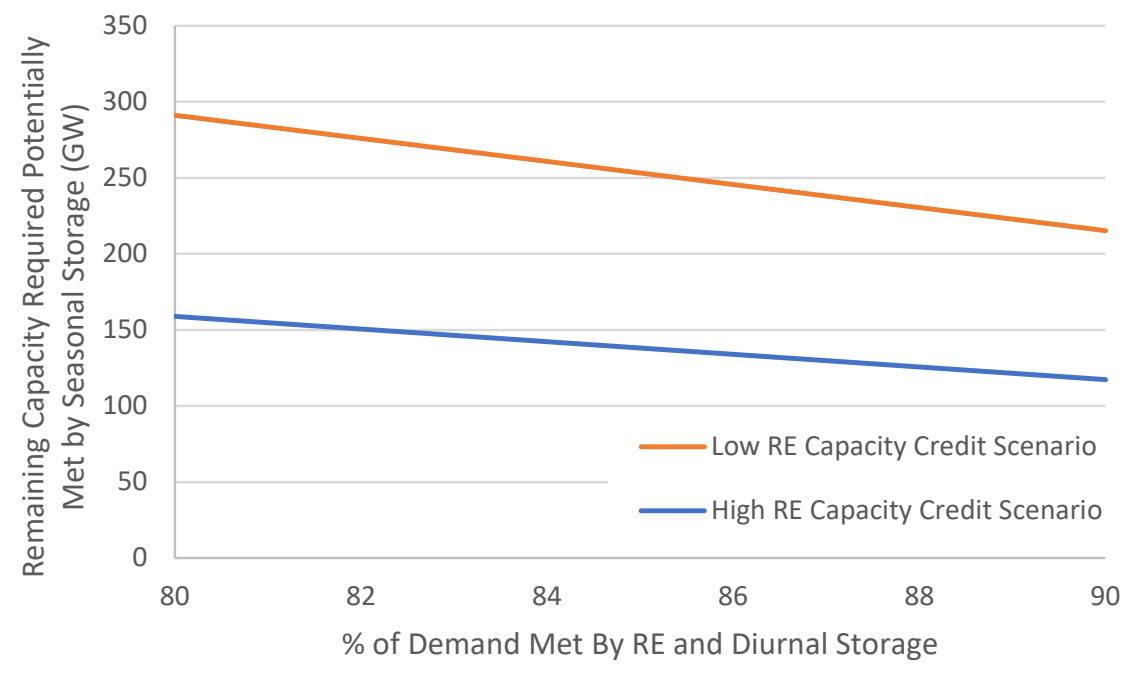

Figure 20. Bounding the size of Phase 4 by estimating the national residual capacity requirements under $80 \%-90 \%$ RE scenarios

\footnotetext{
34 This represents the results of 2,000 combinations of wind, solar and diurnal storage, along with other RE resources, allowing for some geothermal and hydroelectric development in addition to the current deployments.
} 


\section{Discussion and Conclusions}

The four phases conceptual framework introduced in this work is a simplification of a more complicated evolution of the stationary energy storage industry and the power system as a whole. However, we believe it is a useful framework to consider the role of different storage technologies, and particularly the importance of duration that will drive adoption in each phase.

Though we acknowledge significant uncertainties, particularly in later phases, Table 4 summaries our four phases framework with estimates of parameters associated with each phase. The premise of the table - and of this work as a whole - is that the value of storage declines incrementally as a function of duration for all grid services. Assuming the cost of most storage technologies increases as a function of duration, there is a strong economic case for deployments following a natural progression from shorter to longer duration. While phases will likely have considerable overlap, transition points between phases will largely be driven by declining value of specific services and associated durations, along with continued cost declines of various storage technologies.

Table 4. Summary of the Four Phase Conceptual Framework

\begin{tabular}{|c|c|c|c|c|}
\hline Phase & Primary Services & $\begin{array}{l}\text { National Deployment Potential } \\
\text { (Capacity) in Each Phase }\end{array}$ & Duration & $\begin{array}{l}\text { Response } \\
\text { Speed }\end{array}$ \\
\hline $\begin{array}{l}\text { Deployment } \\
\text { prior to } \\
2010\end{array}$ & $\begin{array}{l}\text { Peaking capacity, } \\
\text { energy time-shifting and } \\
\text { operating reserves }\end{array}$ & $23 \mathrm{GW}$ of PSH & $\begin{array}{l}\text { Mostly } \\
8-12 \mathrm{hr}\end{array}$ & Varies \\
\hline 1 & Operating reserves & $<30 \mathrm{GW}$ & $<1 \mathrm{hr}$ & $\begin{array}{l}\text { Milliseconds } \\
\text { to seconds }\end{array}$ \\
\hline 2 & Battery peaking capacity & $\begin{array}{l}40-100 \mathrm{GW} \text {, strongly linked } \\
\text { to PV deployment }\end{array}$ & $2-6 \mathrm{hr}$ & Minutes \\
\hline 3 & $\begin{array}{l}\text { Diurnal capacity and } \\
\text { energy time-shifting }\end{array}$ & $\begin{array}{l}100+\text { GW. Depends on both } \\
\text { on Phase } 2 \text { and deployment } \\
\text { of VRE resources }\end{array}$ & $4-12 \mathrm{hr}$ & Minutes \\
\hline 4 & $\begin{array}{l}\text { Multiday to seasonal } \\
\text { capacity and energy } \\
\text { time-shifting }\end{array}$ & Zero to more than $250 \mathrm{GW}$ & $>12 \mathrm{hr}$ & Minutes \\
\hline
\end{tabular}

The four phases framework points to the need for appropriate expectations about factors such as the value of very fast responding energy storage devices. With the exception of frequency response and frequency regulation services, nearly all grid services can be met with devices that can ramp in the minute-to-hour time frame, and faster response is not needed to provide these services. In addition, the market for the very fast response needed to provide frequency response and frequency regulation services is inherently limited, and growth in VRE deployment will likely have limited impact on the overall size of the fast response markets. 
The key opportunity for storage beyond the quickly saturating operating reserves markets is the vast need for capacity that can be available during peak demand periods, starting with the roughly 4-hour long summer peaks experienced in much of the United States. This transitions to longer durations because of the simple geometry of how storage flattens load patterns, which is offset by increased VRE deployment, with PV deployment appearing to be the strongest factor behind this opportunity. Beyond this diurnal opportunity lies an uncertain scenario of deep decarbonization that potentially involves renewably fueled generators associated with multiday and seasonal storage with deployments that could also be measured in hundreds of gigawatts. This phase is also associated with deployment of technologies that enable multi-sector decarbonization via fuels production.

Of course, disruptive technology or market pathways could alter the vision we present here. Though we do not explicitly consider behind-the-meter or distribution-sited storage, we would anticipate a similar pattern of deployment, particularly if tariffs reflect the fundamental costs and values associated with the generation and delivery of reliable electricity service. Alternative pathways that potentially compete with storage could include demand response, perhaps including ubiquitous real-time pricing or other mechanisms that provide intelligent appliances and devices the ability to match demand and supply to minimize costs. Vehicle electrification represents a significant uncertainty in terms of controlled charging and even vehicle-to-grid technologies. Alternatively, the use of DC fast charging could motivate the need for additional stationary storage, particularly in areas of significant transmission congestion or other load pockets. Additionally, if storage technologies evolve such that long-duration storage can be built at the same or lower cost than shorter-duration storage (or are developed for cross-sector applications), the phases discussed here might unfold differently.

The large number of technology options available for balancing supply and demand also points to additional analytic needs for utilities and stakeholders to consider optimal least-cost portfolios. Traditional planning methods may need to be reconsidered with the impact of VRE and storage resources on traditional metrics such as planning reserve margin. New planning approaches may be needed to evaluate the ability of energy storage to provide reliable service while helping achieve regional climate goals at minimum cost.

In summary, our framework of four future phases of energy storage deployment can inform our understanding of the emerging and modeled energy future that may rely on significant new options, markets, and value in combination with variable renewable energy. Many of the concepts and themes we introduce in this work will be examined more fully in other parts of the Storage Futures Study 


\section{References}

1. EIA, Electric Power Annual (2019).

2. , Introduction to System Integration of Renewables - Analysis. IEA (December 18, 2020).

3. P. Denholm, E. Ela, B. Kirby, M. Milligan, The Role of Energy Storage with Renewable Electricity Generation. Technical Report, 61 (2010).

4. D. Huertas Hernando, et al., Hydro power flexibility for power systems with variable renewable energy sources: An IEA Task 25 collaboration. Wiley Interdisciplinary Reviews: Energy and Environment 6 (2016).

5. U. Helman, B. Kaun, J. Stekli, Development of Long-Duration Energy Storage Projects in Electric Power Systems in the United States: A Survey of Factors Which Are Shaping the Market. Frontiers in Energy Research 8, 275 (2020).

6. P. O'connor, et al., "Hydropower Vision A New Chapter for America's 1st Renewable Electricity Source" (Oak Ridge National Lab. (ORNL), Oak Ridge, TN (United States), 2016) https:/doi.org/10.2172/1502612 (March 18, 2020).

7. C. Augustine, N. Blair, "Storage Technology Modeling Input Data Report."

8. PJM, “2017 PJM Annual Report” (2017).

9. Independent System Operator-New England (ISO-NE), “Annual Markets Report.” (2018).

10. J. Bistline, et al., Energy storage in long-term system models: a review of considerations, best practices, and research needs. Progress in Energy 2, 032001 (2020).

11. A. D. Mills, R. H. Wiser, "An evaluation of solar valuatoin methods used in utility planning and procurement procedures" (Lawrence Berkeley National Lab. (LBNL), Berkeley, CA (United States), 2013) (March 17, 2020).

12. FERC, Energy Primer A Handbook of Energy Market Basics April 2020. 150 (2020).

13. P. L. Denholm, Y. Sun, T. T. Mai, "An Introduction to Grid Services: Concepts, Technical Requirements, and Provision from Wind" (National Renewable Energy Lab. (NREL), Golden, CO (United States), 2019) https:/doi.org/10.2172/1505934 (March 17, 2020).

14. NERC, "NERC Glossary."

15. Electric Power Research Institute (EPRI)., Wholesale Electricity Market Design Initiatives in the United States: Survey and Research Needs. Palo Alto, CA: EPRI. 3002009273. (2016).

16. M. Hummon, P. Denholm, J. Jorgenson, D. Palchak, Fundamental Drivers of the Cost and Price of Operating Reserves. Renewable Energy, 57 (2013). 
17. E. Ela, R. Hytowitz, U. Helman, Ancillary Services in the United States: Technical Requirements, Market Designs, and Price Trends (EPRI, 2019).

18. E. Ela, M. Milligan, B. Kirby, "Operating Reserves and Variable Generation” (National Renewable Energy Lab. (NREL), Golden, CO (United States), 2011) https:/doi.org/10.2172/1023095 (March 17, 2020).

19. DOE and EIA, "EIA and DOE storage Databases."

20. R. Sioshansi, S. H. Madaeni, P. Denholm, A Dynamic Programming Approach to Estimate the Capacity Value of Energy Storage. IEEE Transactions on Power Systems 29, 395-403 (2014).

21. F. D. Munoz, A. D. Mills, Endogenous Assessment of the Capacity Value of Solar PV in Generation Investment Planning Studies. IEEE Transactions on Sustainable Energy 6, $1574-1585$ (2015).

22. A. D. Mills, R. H. Wiser, Changes in the economic value of photovoltaic generation at high penetration levels: A pilot case study of California in 2012 IEEE 38th Photovoltaic Specialists Conference (PVSC) PART 2, (2012), pp. 1-9.

23. A. W. Frazier, W. Cole, P. Denholm, D. Greer, P. Gagnon, Assessing the potential of battery storage as a peaking capacity resource in the United States. Applied Energy 275, 115385 (2020).

24. St. John, “Taking Aim at PJM’s 10-Hour Duration Capacity Rule for Energy Storage."

25. PJM, "Default MOPR Floor Offer Prices for New Generation Capacity Resources" (2020).

26. MISO, “Cost of New Entry PY 2020/21” (2019).

27. J. Eichman, A. Townsend, M. Melaina, "Economic Assessment of Hydrogen Technologies Participating in California Electricity Markets" (National Renewable Energy Laboratory, 2016).

28. P. Albertus, J. Manser, S. Litzelman, Long-duration electricity storage applications, economics, and technologies. Joule 4, 21-32 (2020).

29. W. Cole, D. Greer, J. Ho, R. Margolis, Considerations for maintaining resource adequacy of electricity systems with high penetrations of PV and storage. Applied Energy 279, 115795 (2020).

30. P. Denholm, et al., The Value of Energy Storage for Grid Applications (NREL, 2013).

31. BNEF, 2019 Long-Term Energy Storage Outlook (Bloomberg New Energy Finance, 2019).

32. Wood Mackenzie Power \& Renewables, "US Energy Storage Monitor report" (2020). 
33. P. L. Denholm, R. M. Margolis, J. D. Eichman, "Evaluating the Technical and Economic Performance of PV Plus Storage Power Plants" (National Renewable Energy Laboratory, 2017) https:/doi.org/10.2172/1376049 (March 5, 2019).

34. R. H. Wiser, et al., Hybrid Power Plants: Status of Installed and Proposed Projects (2020).

35. P. Denholm, J. Nunemaker, P. Gagnon, W. Cole, The potential for battery energy storage to provide peaking capacity in the United States. Renewable Energy (2019) https:/doi.org/10.1016/j.renene.2019.11.117.

36. A. D. [Lawrence B. N. L. (LBNL) Mills Berkeley, CA (United States)], R. H. [Lawrence B. N. L. (LBNL) Wiser Berkeley, CA (United States)], J. [Lawrence B. N. L. (LBNL) Seel Berkeley, CA (United States)], "Power Plant Retirements: Trends and Possible Drivers" (2017) https:/doi.org/10.2172/1411667.

37. P. Denholm, T. Mai, Timescales of energy storage needed for reducing renewable energy curtailment. Renewable Energy 130, 388-399 (2019).

38. T. M. Jennie Jorgenson, Reducing Wind Curtailment through Transmission Expansion in a Wind Vision Future (2017) (January 19, 2020).

39. T. Mai, D. Mulcahy, M. M. Hand, S. F. Baldwin, Envisioning a renewable electricity future for the United States. Energy 65, 374-386 (2014).

40. J. Cochran, T. Mai, M. Bazilian, Meta-analysis of high penetration renewable energy scenarios. Renewable and Sustainable Energy Reviews 29, 246-253 (2014).

41. M. F. Ruth, B. S. Pivovar, J. D. Eichman, Hydrogen's Expanding Role in the Energy System. Chemical Engineering Progress 115 (2019).

42. M. Perez, R. Perez, K. R. Rábago, M. Putnam, Overbuilding \& curtailment: The costeffective enablers of firm PV generation. Solar Energy 180, 412-422 (2019).

43. J. D. Jenkins, M. Luke, S. Thernstrom, Getting to Zero Carbon Emissions in the Electric Power Sector. Joule 2, 2498-2510 (2018).

44. N. A. Sepulveda, J. D. Jenkins, F. J. de Sisternes, R. K. Lester, The Role of Firm LowCarbon Electricity Resources in Deep Decarbonization of Power Generation. Joule 2, 2403-2420 (2018). 


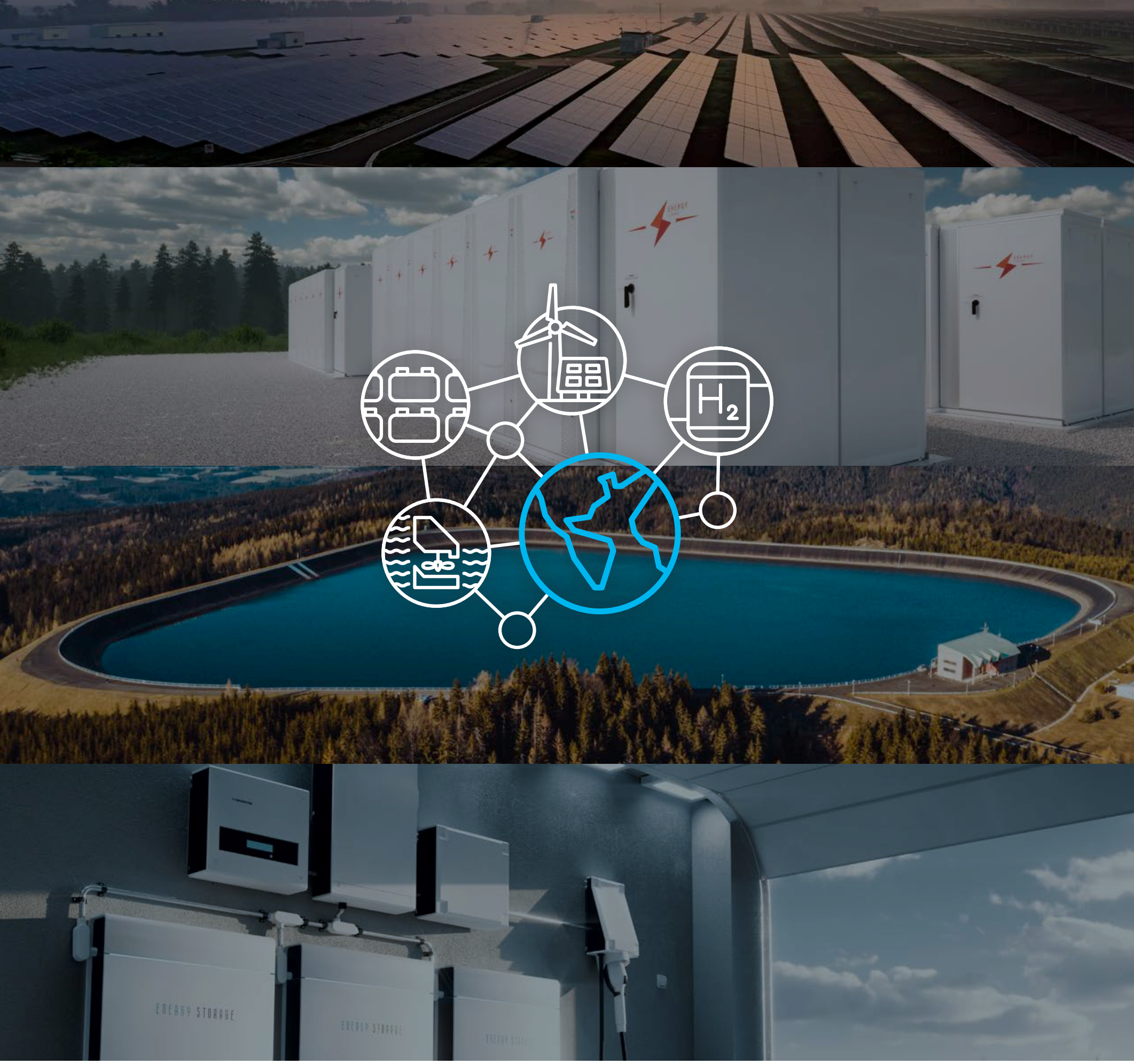

\section{BNREL Transforming ENERGY}

National Renewable Energy Laboratory

15013 Denver West Parkway, Golden, CO 80401 303-275-3000 • www.nrel.gov

NREL prints on paper that contains recycled content.
NREL is a national laboratory of the U.S. Department of Energy Office of Energy Efficiency and Renewable Energy Operated by the Alliance for Sustainable Energy, LLC NREL/TP-6A20-77480 • January 2021 